\title{
Methotrexate-coupled nanoparticles and magnetic nanochemothermia for the relapse-free treatment of T24 bladder tumors
}

This article was published in the following Dove Press journal:

International Journal of Nanomedicine

6 April 2017

Number of times this article has been viewed

\section{Marcus Stapf \\ Ulf Teichgräber \\ Ingrid Hilger}

Department of Experimental Radiology, Institute of Diagnostic and Interventional Radiology, Jena University Hospital, Friedrich-Schiller University Jena, Jena, Germany
Correspondence: Ingrid Hilger Department of Experimental Radiology, Institute of Diagnostic and Interventional Radiology, Jena University Hospital, Forschungszentrum Lobeda, Am Klinikum I, D-07747 Jena, Germany Tel +49364I 932592I Email ingrid.hilger@med.uni-jena.de
Abstract: Heat-based approaches have been considered as promising tools due to their ability to directly eradicate tumor cells and/or increase the sensitivity of tumors to radiation- or chemotherapy. In particular, the heating of magnetic nanoparticles (MNPs) via an alternating magnetic field can provide a handy alternative for a localized tumor treatment. To amplify the efficacy of magnetically induced thermal treatments, we elucidated the superior tumor-destructive effect of methotrexate-coupled MNPs (MTX/MNPs) in combination with magnetic heating (nanochemothermia) over the thermal treatment alone. Our studies in a murine bladder xenograft model revealed the enormous potential of nanochemothermia for a localized and relapse-free destruction of tumors which was superior to the thermal treatment alone. Nanochemothermia remarkably fostered the reduction of tumor volume. It impaired proapoptotic signaling (eg, p-p53), cell survival (eg, p-ERK1/2), and cell cycle (cyclins) pathways. Additionally, heat shock proteins (eg, HSP70) were remarkably affected. Moreover, nanochemothermia impaired the induction of angiogenic signaling by decreasing, for example, the levels of VEGF-R1 and MMP9, although an increasing tumor hypoxia was indicated by elevated Hif- $1 \alpha$ levels. In contrast, tumor cells were able to recover after the thermal treatments alone. In conclusion, nanochemothermia on the basis of MTX/MNPs was superior to the thermal treatment due to a modification of cellular pathways, particularly those associated with the cellular survival and tumor vasculature. This allowed very efficient and relapse-free destruction of tumors.

Keywords: bladder cancer, magnetic heating, magnetic nanoparticles, methotrexate, hyperthermia, mouse xenograft

\section{Introduction}

Until now, the relapse of insufficiently treated tumors poses an immense problem in the treatment of cancer. In this regard, especially bladder cancer exhibits a high recurrence $(60 \%-70 \%)$ even after the complete removal of the bladder (transurethral resection), with $25 \%$ of the recurring tumors progressing to a higher tumor stage or grade. ${ }^{1}$ Additionally, an increased resistance of bladder cancer cells to ionizing radiation due to a high frequency of p53 mutations impedes a successful treatment. ${ }^{2}$ Moreover, remarkable problems of intravesically or systemically applied antitumor therapies arise from the very heterogenic interpatient efficacy and severe side-effects. For this reason, thermal approaches are considered as promising tools for the treatment of cancer due to the ability of eradicating tumor cells and/or increasing the sensitivity of cancer cells to radiation- or chemotherapy. ${ }^{3-7}$ The temperature for thermal treatments can be achieved by various strategies including water bath, infrared light, microwave 
wave heating, radiofrequency radiation, and ultrasound. Nevertheless, most treatment regimens lead to an unspecific and unlocalized heating of tissues (eg, by whole body hyperthermia), limiting the maximal applicable temperature and therefore therapy efficiency.

In this context, magnetic heating can provide a handy alternative for a localized heating and inactivation of cancer cells with low side-effects. ${ }^{8-11}$ Thus, magnetic nanoparticles (MNPs) can be deposited in the target tissue (eg, by intratumoral injection) and adjustably heated afterward by using an alternating magnetic field (AMF).

Basically, heat-based treatments can be divided into two groups, depending on the applied temperatures over the treatment time (thermal dose): hyperthermia and thermoablation. ${ }^{12}$ For hyperthermal treatments, temperatures between $\sim 41^{\circ} \mathrm{C}$ and $45^{\circ} \mathrm{C}$ are used. This temperature range is known to induce reversible cellular damage and apoptosis by affecting the metabolism of (cancer) cells, RNA/DNA synthesis, DNA repair mechanisms, membrane fluidity and stability, the function of cell surface receptors, and transmembrane transport proteins. ${ }^{5,13,14}$ In the case of thermoablative treatments, higher temperatures $\left(50^{\circ} \mathrm{C}\right.$ or higher) are applied. ${ }^{15,16}$ These high temperatures cause necrosis even after a relatively short time of thermal exposure, by inducing irreversible cellular damage, such as the inhibition of DNA repair, and protein denaturation. ${ }^{17}$

To further amplify the effect of magnetic heating alone, a combinatory treatment of the target tissue by an additional coupling of drugs (eg, chemotherapeutics) to the MNPs is possible. ${ }^{18}$ In this regard, the chemotherapeutic drug methotrexate (MTX), an antifolate which interferes with the cellular nucleotide metabolism and DNA synthesis, was shown to be coupled stably to MNPs (MTX/MNPs) and exhibited a comparable toxicity to free MTX. ${ }^{19,20}$ This combinatory "nanochemothermal" approach is thought to allow a more efficient treatment of tumors, as the MNPs, and therefore the MTX, will remain in the tumor region over several days, allowing a repeated thermal, and a constant chemotherapeutic treatment, which is localized to the tumor region. ${ }^{20,21}$ Moreover, the utilization of magnetic heating in combination with MTX/MNPs has the ability to interfere with multiple phases of the cell cycle. In particular, heat-based treatments are reported to interfere mostly with later phases of the cell cycle (eg, S or M phase), whereas MTX acts in earlier phases, such as at G1/S transition. ${ }^{22-26}$

Besides the regulation of proteins involved in proliferation, apoptosis, and cell cycle, especially angiogenic factors are known to be key players in tumor formation and reoccurrence in vivo. Up to now, heat-based cancer therapies have been primarily studied via in vitro models using externally applied heating. Hence, knowledge concerning the ability of magnetic heating to inhibit the tumor growth and the related fundamental changes on the protein level in vivo, particularly when used as part of a combinatory treatment, is very limited. In this context, it is of major interest to analyze the impact of magnetically induced nanochemothermal treatment onto tumor growth and correlate the data with important processes, such as apoptosis, cell cycle, and angiogenesis. The results of this work will help to estimate the therapeutic efficiency of magnetic heating when used as combinatory treatment with MTX/MNPs (nanochemothermia).

In the present investigation, we studied the impact of a magnetically induced nanochemothermal treatment using MTX/MNPs and validated its superior efficiency on the fast and relapse-free destruction of bladder tumors by comparison with the application of a localized thermal treatment alone. We also analyzed the impact of the presence of MTX/MNPs or the bare MNPs on the abovementioned effect. Furthermore, the associated mechanisms for tumor destruction were explored by studying the regulation of key proteins involved in apoptosis, cellular survival, angiogenesis, and cell cycle.

\section{Materials and methods Cells and cell culture conditions}

A human bladder cancer cell line (T24, transitional cell carcinoma, grade III) was chosen, as bladder tumors exhibit a good accessibility for magnetic heating treatments. T24 cells were cultured in Dulbecco's Modified Eagle's Medium/F-12 supplemented with 5\% fetal bovine serum (Life Technologies, Carlsbad, CA, USA). All experiments were performed without any antibiotics/antimycotics, except in the case of in vitro hyperthermia, where penicillin/streptomycin (1:100, Gibco, Germany) was added to the cell culture media. Prior to usage, cells were authenticated by the DSMZ (Deutsche Sammlung von Mikroorganismen und Zellkulturen $\mathrm{GmbH}$, Germany).

\section{Preparation of MTX/MNPs and MTX release kinetics}

Throughout all MNP-related experiments and for the preparation of MTX-coupled MNPs (MTX/MNPs), we used $200 \mathrm{~nm}$ fluidMAG-ARA/T12 MNPs (chemicell GmbH, Germany), which exhibited an arachidonic acid (ARA) coating and a clustered iron oxide core (diameter $\sim 165 \mathrm{~nm}$ ). The clustered magnetite core was made up of multiple smaller single core particles with a diameter of $\sim 12 \mathrm{~nm}$. MTX (AppliChem, 
Darmstadt, Germany) was covalently coupled to MNPs by addressing the amine groups of MTX with the aid of 1-ethyl-3-(3-dimethylaminopropyl)carbodiimide (EDC, Sigma-Aldrich, St Louis, MO, USA) as coupling agent. After the magnetic separation (MagneSphere ${ }^{\circledR}$ Technology, Promega, Fitchburg, WI, USA), the coupled particles were repeatedly washed with phosphate-buffered saline (PBS) and all supernatants were collected. The coupling efficiency was determined by measuring the amount of free MTX in the supernatants of all washing steps at $302 \mathrm{~nm}$ in a 96-well plate using a plate reader (Tecan Infinite M1000 pro, Tecan Trading AG, Switzerland).

In addition, the release of MTX from the MNPs was investigated over time. For this purpose, washed MTX/MNPs were incubated for another $2,24,48$, or $72 \mathrm{~h}$ with either a standard PBS solution ( $\mathrm{pH}$ 7.4) to simulate physiological conditions, or acidic PBS ( $\mathrm{pH} 5$ ) to mimic conditions after an uptake of MTX/MNPs into cells. ${ }^{27}$ Stability of MTX after $1 \mathrm{~h}$ incubation at $44^{\circ} \mathrm{C}$ was verified by high performance liquid chromatography routine analyses (data not shown).

\section{Particle characterization (hydrodynamic diameter, zeta potential, and specific absorption rate $[\mathrm{SAR}]$ )}

For all used MNP formulations, the hydrodynamic diameter and the zeta potential were determined using a Zetasizer Nano ZS and DTS1061 disposable capillary cells (both Malvern Instruments $\mathrm{GmbH}$, Germany). The hydrodynamic diameter ( $z$-average) was measured in quintuplicates by dynamic light scattering, and the zeta potential ( $\zeta$-potential), representing the particle's surface charge, was measured in triplicates.

The SAR of the used MNPs was determined as described elsewhere using an $\operatorname{AMF}(\mathrm{H}=15.4 \mathrm{kA} / \mathrm{m}, \mathrm{f}=435 \mathrm{kHz}) .{ }^{11,28}$ For this purpose, temperatures were acquired by a fiber optic temperature sensor and a fiber optic thermometer (TS5 and FOTEMPMK-19, both OPTOCON AG, Germany), and the relevant iron concentrations were determined in triplicates by atomic absorption spectroscopy (AAS). The SAR of immobilized MNPs, as occurring after cellular internalization and/or binding, was measured after their immobilization in polyvinyl alcohol (PVA 10\%, w/v, Sigma-Aldrich). ${ }^{11,29-31}$ High resolution electron microscopy (HRTEM) pictures of MNPs were obtained as described elswere. ${ }^{11}$

\section{Quantification of intracellular iron content by AAS}

The cellular uptake of either MTX/MNPs or MNPs was analyzed by AAS to estimate the impact of the
MTX-functionalization on cellular internalization. At $24 \mathrm{~h}$ after cell seeding, $100 \mu \mathrm{g} / \mathrm{mL}$ of the either MTX/MNPs or MNPs were added to the cells and incubated for another 24, 48 , or $72 \mathrm{~h}$ at $37^{\circ} \mathrm{C}$ and $5 \% \mathrm{CO}_{2}$. The media were discarded and noninternalized particles were removed by washing thrice with Hanks' Salt Solution (HBSS, Biochrom GmbH, Germany). Cell numbers were determined using a CASY ${ }^{\circledR}$ Cell Counter (Cell Counter + Analyser System Modell TT, innovates AG, CASY ${ }^{\circledR}$-Technology, Germany). Afterward, the harvested cells were centrifuged $(200 \times g, 5 \mathrm{~min})$ thrice, with washing the pellet with HBSS in between.

Pellets were incubated with $32 \% \mathrm{HCl}(\mathrm{v} / \mathrm{v}$, extra pure, Carl Roth GmbH, Germany) at ambient temperature and mixed thoroughly to ensure complete sample dissociation. To remove proteins that may interfere with the iron determination, a protein precipitation step using $10 \%$ trichloroacetic acid (w/v, Carl Roth $\mathrm{GmbH}$ ) was performed directly before measurement. Afterward, the resulting supernatant was carefully transferred to a fresh vial and used for iron determination via AAS using an AAS 5 FL spectrometer (Analytik Jena AG, Germany). Finally, the iron content of the sample was normalized to the counted number of cells.

\section{In vitro hyperthermia and cytotoxicity assay}

To analyze the impact of nanochemothermia on cellular vitality, in vitro hyperthermia was performed and compared to the treatment with either MNPs/AMF, MTX/MNPs, or MNPs. Cells without further additives served as negative control. At $24 \mathrm{~h}$ after cell seeding, either MTX/MNPs, MNPs (both $100 \mu \mathrm{g} / \mathrm{mL}$ ), or $25 \mu \mathrm{g} / \mathrm{mL}$ MTX (MTX/ MNP-corresponding MTX concentration) were added to the cells. After another $24 \mathrm{~h}$ of incubation, noninternalized nanoparticles and MTX were removed from the cells by washing with HBSS and the cell number was determined. Cells were placed in an $\mathrm{AMF}(\mathrm{H}=23.9 \mathrm{kA} / \mathrm{m}, \mathrm{f}=410 \mathrm{kHz})$ in a water-perfused insulator and magnetically heated to a target temperature of $44^{\circ} \mathrm{C}$ for the duration of $1 \mathrm{~h}$. Temperatures were controlled via fiber optic temperature sensors (TS5 and FOTEMPMK-19, Optocon AG) and adjusted by adapting the power of the AMF whenever necessary. Treatment groups without $\mathrm{AMF}$ were placed in an incubator at $37^{\circ} \mathrm{C}$ for the same period of time. Immediately after treatment, cells were seeded into 96-well plates, and the cellular viability was assessed after another 24- or 48-h incubation (corresponding to 2 or $3 \mathrm{~d}$ after nanoparticle addition) based on the mitochondrial dehydrogenase activity using AlamarBlue ${ }^{\circledR}$ Cell Proliferation Reagent (Life Technologies, Germany) 
and a fluorescence plate reader (excitation/emission: $545 \mathrm{~nm} / 590 \mathrm{~nm}$, Tecan Infinite M1000 Pro, Tecan Group Ltd., Switzerland).

\section{Murine xenografts and tumor implantation}

All animal experiments were performed in accordance with international guidelines on the ethical use of animals and were approved by the regional animal care committee (Thüringer Landesamt für Verbraucherschutz, Bad Langensalza, Germany). Whenever necessary, animals were anesthetized using 2\%-2.5\% isoflurane (Aktavis, Germany). Tumors were induced subcutaneously (tumor take rate $>90 \%$ ) by injecting $200 \mu \mathrm{L}$ of Matrigel ${ }^{\mathrm{TM}}$ (BD Matrigel $^{\mathrm{TM}}$ Basement Membrane Matrix; Becton Dickinson GmbH, Germany) containing $2 \times 10^{6} \mathrm{~T} 24$ cancer cells dorsally between the hindlegs of 8 - and 10-week-old male SCID (BALB/cJHanHsd-Prkdc; Harlan Laboratories, the Netherlands). Experiments started when the tumors reached a volume $>150 \mathrm{~mm}^{3}(\sim 14 \mathrm{~d}$ after injection). The tumor growth was controlled at least twice a week to ensure animal health. Tumor volumes were calculated using the following equation: $V=\frac{\pi}{6} \times$ length $_{\text {tumor }} \times$ width $_{\text {tumor }} \times$ height $_{\text {tumor }}$.
Animal groups, nanoparticle application, and survey of intratumoral distribution

Animals were divided (randomized) into five independent experimental groups. Group 1 (nanochemothermia, MTX/ MNPs/AMF, $n=8)$ received MTX/MNPs and was treated in an AMF for 60 min. Group 2 (thermal treatment, MNPs/ AMF, $n=10$ ) received MNPs (without MTX) and additional AMF exposure in order to investigate the impact of the performed thermal treatment on tumor growth and protein expression alone. Group 3 received MTX/MNPs $(n=13)$ to assess the influence of MTX coupled to nanoparticles on tumor destruction and protein regulation. Group $4(n=13)$ received MNPs in order to control their role in the chemothermal effects. Groups 3 and 4 were not exposed to an AMF. Animals of Group 5 (negative control, $n=6$ ) remained untreated and served as negative control group.

At $24 \mathrm{~h}$ prior to AMF exposure (day -1), anesthetized animals of the appropriate treatment groups received an intratumoral injection of the corresponding nanoparticles $\left(1 \mu \mathrm{g}_{\mathrm{Fe}} /\right.$ $\mathrm{mm}_{\text {tumor }}^{3} ;$ Figure 1A). During nanoparticle injection, the cannula was slightly moved to improve particle distribution. The tumoral distribution of applied nanoparticles (MTX/MNPs or MNPs) was analyzed three-dimensionally (day 0) using a TomoScope ${ }^{\circledR}$ Synergy Twin micro-computed tomography

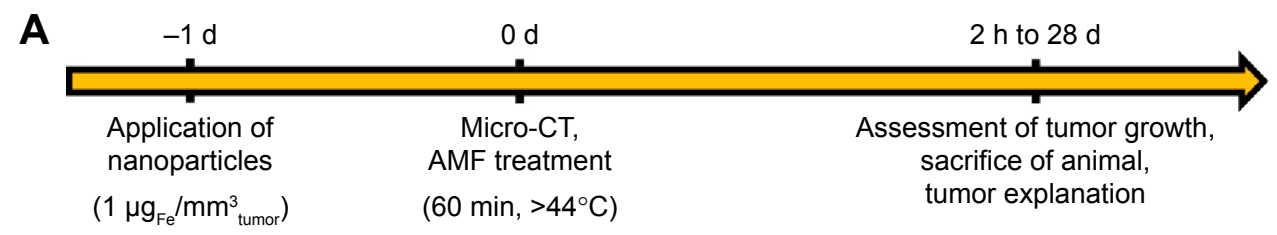

B

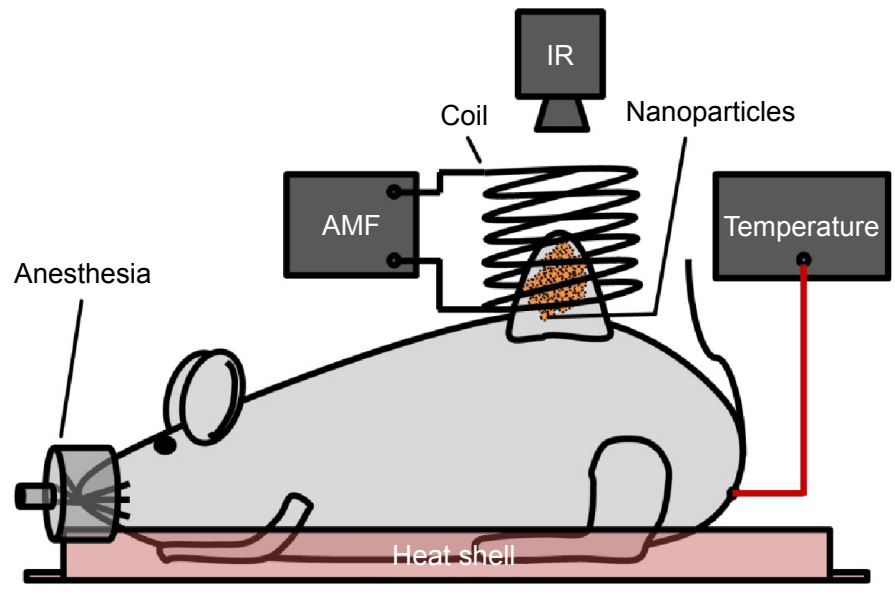

Figure I Treatment scheme (A) and experimental setup (B) for in vivo experiments.

Notes: (A) Applied treatment scheme for the performed in vivo experiments. (B) Magnetic heating was induced by exposing the intratumorally applied nanoparticles (orange spots) to an $A M F(H=23.9 \mathrm{kA} / \mathrm{m}, \mathrm{f}=410 \mathrm{kHz})$. An IR was placed vertically above the tumor/coil for acquiring tumor surface temperatures (heat maps). Body temperature was controlled rectally via fiber optic temperature sensors. Anesthetized mice were placed in a water-perfused heat shell to prevent hypothermia during treatment. Copyright C2017. Dove Medical Press. Adapted from Stapf M, Pömpner N, Kettering M, Hilger I. Magnetic thermoablation stimuli alter BCL2 and FGF-RI but not HSP70 expression profiles in BT474 breast tumors. Int J Nanomedicine. 2015;10(10):1931-1939.17

Abbreviations: AMF, alternating magnetic field; CT, computerized tomography; IR, infrared thermography camera. 
(CT) scanner and the ImpactCB software (both CT Imaging $\mathrm{GmbH}$, Germany; <200 mGy/scan, spatial resolution of $114 \mu \mathrm{m})$. The applied low radiation dose is expected not to influence the outcome of the performed study. ${ }^{32} 3 \mathrm{D}$ micro-CT data were analyzed via the Imalytics Research Software (Philips Technologie GmbH, Germany). Tumor growth was observed up to $28 \mathrm{~d}$ after AMF exposure $(\mathrm{H}=23.9 \mathrm{kA} / \mathrm{m}$, $\mathrm{f}=410 \mathrm{kHz}$ ), whereas the tumors for Western blot analyses were explanted at 2, 24, or $48 \mathrm{~h}$.

\section{In vivo nanochemothermal therapy and CEM43T90 calculation}

For heat-based treatments (day 0), the anesthetized animals were exposed to an $\operatorname{AMF}(\mathrm{H}=23.9 \mathrm{kA} / \mathrm{m}, \mathrm{f}=410 \mathrm{kHz})$ at $24 \mathrm{~h}$ after nanoparticle application. To maintain body temperature and prevent hypothermia, animals were placed on a heat shell during treatment. Throughout the magnetic heating, tumor surface temperatures were monitored using an infrared thermography camera (InfRec R300, Nippon Avionics Co., Japan). In addition, the body temperature was monitored rectally via a fiber optic temperature sensor (TS5 and FOTEMPMK-19, Optocon AG). Tumoral temperatures were adjusted by adapting the power of the AMF to achieve target temperatures of $44^{\circ} \mathrm{C}$ at the tumor margins. As a result, central tumor temperatures of up to $50^{\circ} \mathrm{C}$ were reached. The experimental setup is depicted in Figure 1B.

To evaluate the quality of the tumoral heat distribution, the cumulative equivalent minutes representing $43^{\circ} \mathrm{C}$ in $90 \%$ of the tumor area (CEM43T90) were calculated from the heat map data gathered by the thermography camera. ${ }^{10,33}$ For this purpose, the heat maps of the treated tumor region were analyzed at every $10 \mathrm{~min}$ after the onset of the AMF, and the corresponding temperature data of every pixel were extracted. From the resulting data, the median CEM43T90 values were calculated for each animal and accordingly for each treatment group.

\section{Analysis of tumor growth}

Observation of tumor growth started at the day of nanoparticle injection (day -1$)$ and was followed up to $28 \mathrm{~d}$ for all treatment groups. For this purpose, the length, width, and height of the tumors were measured in vivo at least twice a week using a caliper. Tumor volumes were calculated with the aforementioned equation and normalized to values of day -1 . The median tumor volume was calculated by calculating the median of all animals within a specific treatment group.

\section{Detection of apoptotic cells of tumor sections}

At $48 \mathrm{~h}$ after AMF exposure, the apoptotic cells of tumor sections were stained by using formalin-fixed and paraffin embedded tumors and the terminal deoxynucleotidyl transferase dUTP nick end labeling (TUNEL) assay (G7132, Promega) based on the manual of instruction. For this approach, tumor specimens were cut into sections $(n=3)$. Slides were deparaffined in xylol and decreasing ethanol concentrations for rehydration. As positive control, slides were additionally treated with DNase I (Roche, Germany) prior to the addition of the TdT reaction mix or without the TdT reaction mix in the case of the negative control. Nuclei were stained with hematoxylin.

\section{Extraction of tumor proteins}

Tumors of sacrificed animals (2, 24, or $48 \mathrm{~h}$ after AMF exposure) were explanted, washed in ice-cold PBS, weighted, and subsequently shock-frozen with liquid nitrogen. Afterward, tumors were homogenized using a tissue lyser (TissueLyser, Qiagen GmbH, Germany), and the total protein was isolated by using radioimmunoprecipitation assay buffer (Sigma, USA) supplemented with protease- (cOmplete, Roche, USA) and phosphatase inhibitors (PhosSTOP, Roche, USA). After centrifugation $\left(20,000 \times \mathrm{g}, 20 \mathrm{~min}, 4^{\circ} \mathrm{C}\right)$, the protein concentration of the resulting supernatant was determined via Bradford method by measuring the absorption at $595 \mathrm{~nm}$ in a plate reader (Tecan Infinite M1000 Pro, Tecan Group Ltd.).

\section{Protein expressions analyses}

Protein regulation of tumors was analyzed at least in duplicates by sodium dodecyl sulfate polyacrylamide gel electrophoresis (SDS-PAGE) and Western blotting. For this purpose, equal protein amounts of all tumors of a specific treatment group were pooled to consider biological and therapeutic diversity. To ensure homogenous protein loading, protein amount of generated pool was measured by Bradford method in triplicates within three independent experiments. Gels ( $7.5 \%$ or $4 \%-20 \%$, Mini-Protean ${ }^{\circledR}$ TGX $^{\text {тм }}$ Gels, Bio-Rad Laboratories Inc., Hercules, CA, USA) were loaded with $30 \mu \mathrm{g}$ of the appropriate pooled protein lysate mixed with SDS loading buffer $(2 \times$ Laemmli Sample Buffer, Bio-Rad Laboratories Inc.). Afterward, proteins were transferred to a polyvinylidene difluoride membrane (Immobilon ${ }^{\circledR}$-P, EMD Millipore Corporation, Billerica, MA, USA) by tank blotting. Blotted membranes were blocked for $1 \mathrm{~h}$ at ambient temperature with either $5 \%$ dry milk (Carl Roth $\mathrm{GmbH}$ ) or $5 \%$ bovine serum 
albumin (Albumin Fraction V, Carl Roth GmbH) in Trisbuffered saline supplemented with $0.1 \%$ Tween-20 (TBST). Whenever required, TBST was used as washing buffer. Membranes were incubated (overnight, $4^{\circ} \mathrm{C}$, mild shaking) with antibodies against proteins involved in apoptosis (p-p53, p21, pro-caspase 8, pro-caspase 3, cleaved PARP), survival (p-Erk1/2, Akt, BCL2, Mcl-1 , HSP70, HSP90), angiogenesis (Hif-1 $\alpha$, VEGF, VEGF-R1, MMP2, MMP9), and cell cycle (cyclin A, cyclin E), diluted in blocking buffer. GAPDH served as a loading control. Membranes were incubated (60 min, ambient temperature, mild shaking) with the appropriate horse radish peroxidase (HRP)-coupled secondary antibody against rabbit (sc-2030) (Santa Cruz Biotechnology, Inc., Dallas, TX, USA) or mouse (sc-2031; 61-6420) (Santa Cruz Biotechnology, Inc.; Invitrogen Corporation, USA). Protein detection was performed using ECL chemoluminescent substrate (EMD Millipore Corporation) and a digital imaging system (ImageQuant LAS 4000, GE Healthcare Europe GmbH, Germany).

\section{Results}

\section{Particle characterization}

The diameters and the polydispersity indices of MTX/MNPs and MNPs were almost comparable between each other, indicating no remarkable influence of the coupling process on particle size and good particle dispersion in aqueous media. At the same time, the coupling of MTX resulted in a slightly more positive $\zeta$-potential of MTX/MNPs compared to MNPs (Figure 2A). HRTEM images (Figure 2B) revealed irregularly clustered multicore particles, exhibiting multiple smaller single core particles, and confirmed the data given by the manufacturer (165-175 nm). The SAR of free (water) and immobilized MNPs was calculated to be 985 or $705 \mathrm{~W} / \mathrm{g}$, respectively (Figure 2C). The coupling efficiency was calculated to be $\sim 250 \mu \mathrm{g}$ MTX per mg MNP. MTX-coupling to MNPs was found to be very stable (even at different temperatures), because $<0.1 \%$ of the MNPbound MTX was released from the particles in either physiological ( $\mathrm{pH} \mathrm{7.4)} \mathrm{or} \mathrm{acidic} \mathrm{(} \mathrm{pH}$ 5) conditions up to $72 \mathrm{~h}$ of incubation (Figure S1).

\section{Preferential and time-dependent uptake of MTX/MNPs in T24 cells}

Cellular iron quantification by AAS showed an effective MTX-functionalization- and a time-dependent uptake of nanoparticles in T24 cells (Figure 3). In this regard, the uptake of MTX/MNPs was always significantly $(P \leq 0.01)$ higher than the uptake of MNPs. The cellular iron concentration after MTX/MNP incubation increased only marginally between 24 and $48 \mathrm{~h}$, but significantly after $72 \mathrm{~h}(P \leq 0.05$; compared to 24 or $48 \mathrm{~h}$ ). Concurrently, higher amounts of MNPs were found with increasing time of incubation.

A

\begin{tabular}{lcccr}
\hline Sample & $\begin{array}{c}\text { Core size } \\
(\mathbf{n m})\end{array}$ & $\begin{array}{c}\text { Hydrodynamic } \\
\text { diameter }(\mathbf{n m})\end{array}$ & $\begin{array}{c}\zeta \text {-potential } \\
(\mathbf{m V})\end{array}$ & PDI \\
\hline MTX/MNPs & $165-175$ & $274.5( \pm 3.6)$ & $-35.9( \pm 0.2)$ & $<0.4$ \\
\hline MNPs & $165-175$ & $283.5( \pm 3.6)$ & $-40.2( \pm 0.4)$ & $<0.4$ \\
\hline
\end{tabular}
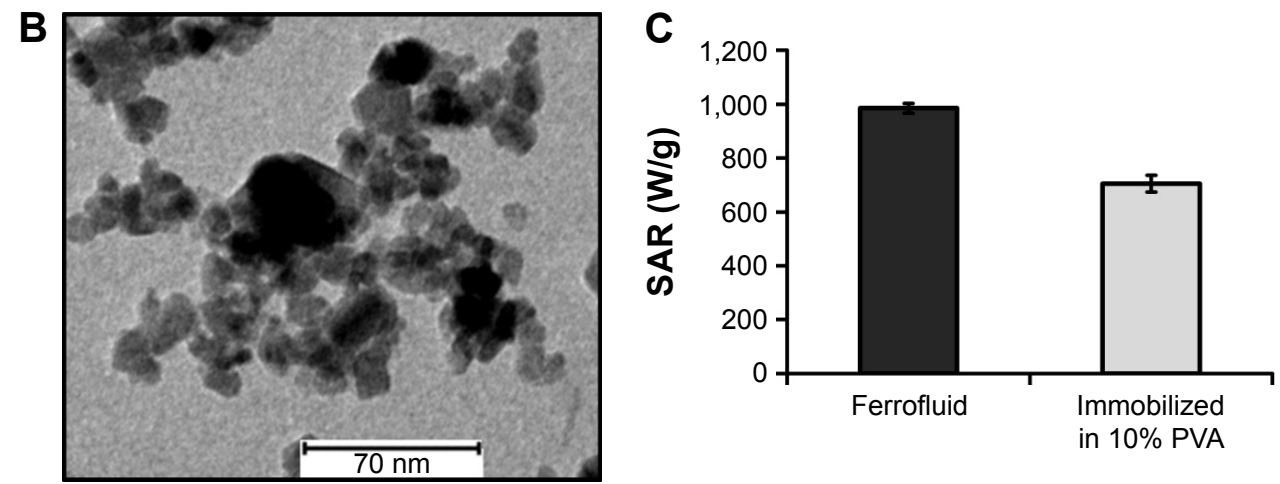

Figure 2 Characterization of the used nanoparticles.

Notes: (A) Core sizes were stated as given in the datasheet of the supplier. The hydrodynamic diameter $(n=5)$ and the $\zeta$-potential $(n=3)$ were analyzed in double distilled water. Standard deviations are given in brackets. (B) Depiction of the clustered particle cores as observed by high resolution transmission electron microscopy. (C) SAR of the used MNPs $(n=3)$ measured as water suspension (ferrofluid) or after immobilization in I0\% PVA.

Abbreviations: MNPs, magnetic nanoparticles; MTX, methotrexate; PDI, polydispersity index; PVA, polyvinyl alcohol; SAR, specific absorption rate. 


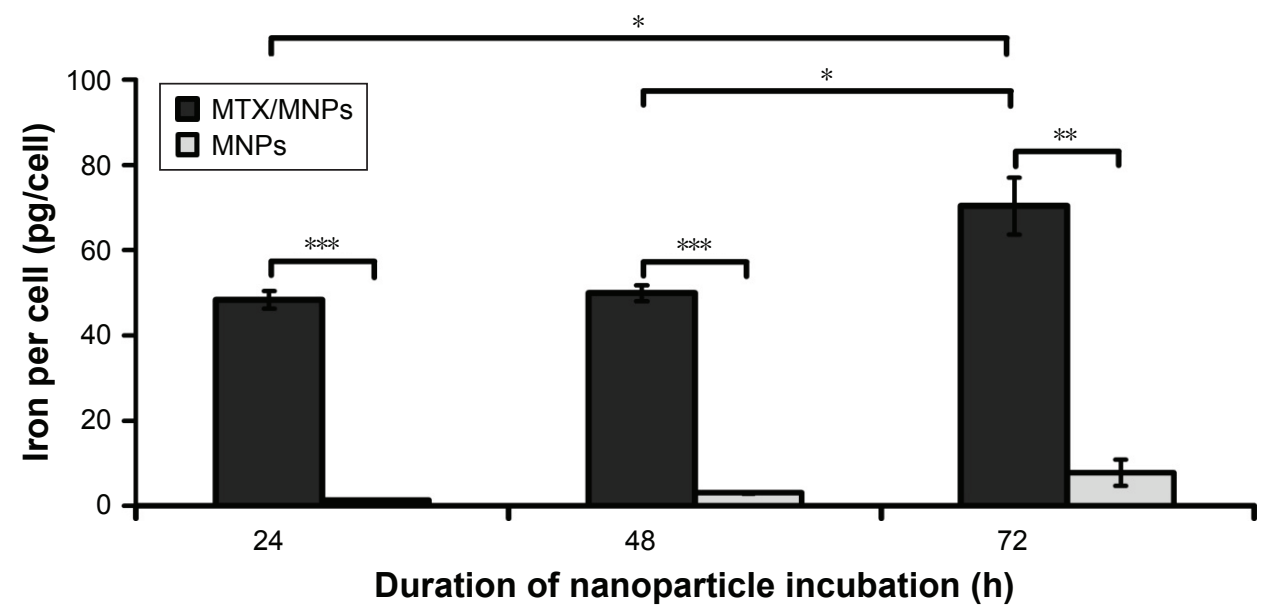

Figure 3 Preferential and time-dependent uptake of MTX/MNPs.

Notes: Cells were incubated with $100 \mu \mathrm{g} / \mathrm{mL}$ of either MTX/MNPs or MNPs (both $\mathrm{n}=3$ ) for the stated period of time, and intracellular iron was quantified by AAS measurements. Results were generated from triplets of two independent experiments. Student's t-test (two-sided, paired) showed significant differences between the groups with $* P<0.05$, $* * P<0.0$ I, and $* * * P<0.001$.

Abbreviations: AAS, atomic absorption spectroscopy; MNPs, magnetic nanoparticles; MTX, methotrexate.

\section{The magnetic heating of MTX/MNPs is suitable for nanochemothermal treatment}

In general, the produced MTX/MNPs were evaluated to be capable of inducing nanochemothermal treatments in vitro. During in vitro hyperthermia experiments, microscopic images of the cells acquired directly before cell harvest were in accordance with the performed AAS measurements (Figure 4A). Subsequently, a changed cellular morphology in the MTX group was observed. Throughout AMF exposure, higher temperatures in the case of MTX/MNPs compared to MNPs $\left(44^{\circ} \mathrm{C}\right.$ vs $\left.39^{\circ} \mathrm{C}\right)$ were achieved (Figure 4B). Cells without any MNPs (MTX, negative control) were only heated to $\sim 38^{\circ} \mathrm{C}$. The highest cytotoxic effect was observed after the nanochemothermal treatment (MTX/MNPs/AMF group; Figure 4C) with increasing incubation time. In contrast, a slight recovery $(\sim 5 \%)$ was found in the MNPs/AMF group at $3 \mathrm{~d}$ after MNP addition. Interestingly, the MTX/MNP group (in the absence of AMF) revealed similar toxicities as observed for the MTX group (independent of the presence of an AMF) at corresponding incubation times. For both points in time, the MNP group was almost comparable to the untreated control group, revealing a low cytotoxicity of the used MNP concentration itself.

\section{Inhomogeneous nanoparticle distribution after intratumoral application}

A heterogenic distribution of the intratumorally injected MNPs was found by micro-CT imaging (Figure 5). At the same time, smaller depositions throughout the whole tumor region were detected. Based on the provided micro-CT data of nanoparticle distribution, the unspecific heating of nontumor tissue or vital organs could be minimized.

\section{Faster destruction of tumors after nanochemothermal treatment}

The application of the nanochemothermal treatment (MTX/ MNPs/AMF) led to a complete destruction of tumors within $12 \mathrm{~d}$ after treatment (Figure 6). In comparison, a remarkably slower tumor destruction (within $18 \mathrm{~d}$ ) was observed after the thermal treatment (MNPs/AMF). These groups showed no relapsing tumors throughout the observation time. Although temperatures of $\sim 44^{\circ} \mathrm{C}$ were achieved at the tumor margins during $\mathrm{AMF}$ exposure, temperatures up to $50^{\circ} \mathrm{C}$ were reached at the tumor center. The median CEM43T90 for the nanochemothermal group and the thermal group was calculated to values of 122 and $155 \mathrm{~min}$, respectively. A steadily increasing tumor growth was found in the absence of AMF exposure. After $28 \mathrm{~d}$, the highest tumor volumes were observed in the negative control group (native tumors), followed by the MTX/MNP and the MNP group.

\section{The induction of apoptosis manifested in the inhibition of tumor growth}

The highest amount of apoptotic cells was detected after nanochemothermia, followed by the thermal treatment (Figure 7). A diffuse TUNEL-positive staining was especially present in the cytoplasm of AMF-treated tumors. Interestingly, almost no apoptotic cells were observed in groups without AMF exposure (MTX/MNPs, MNPs, negative control), 
A

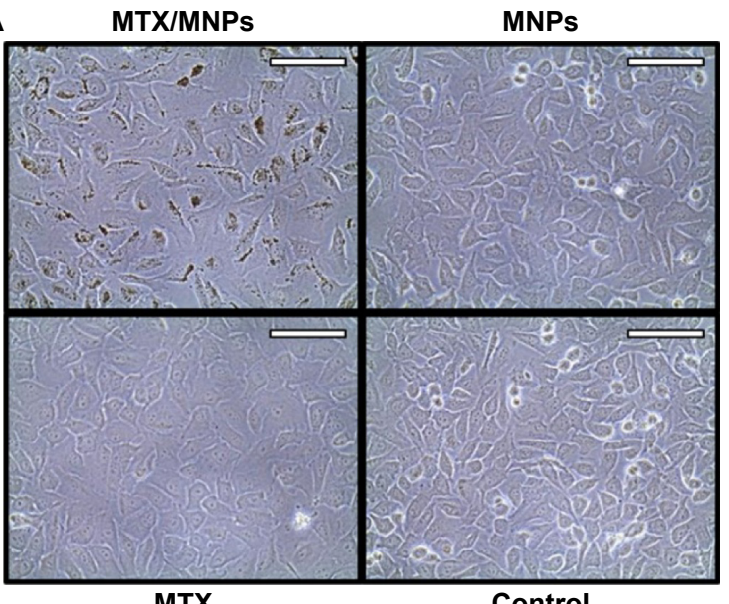

B

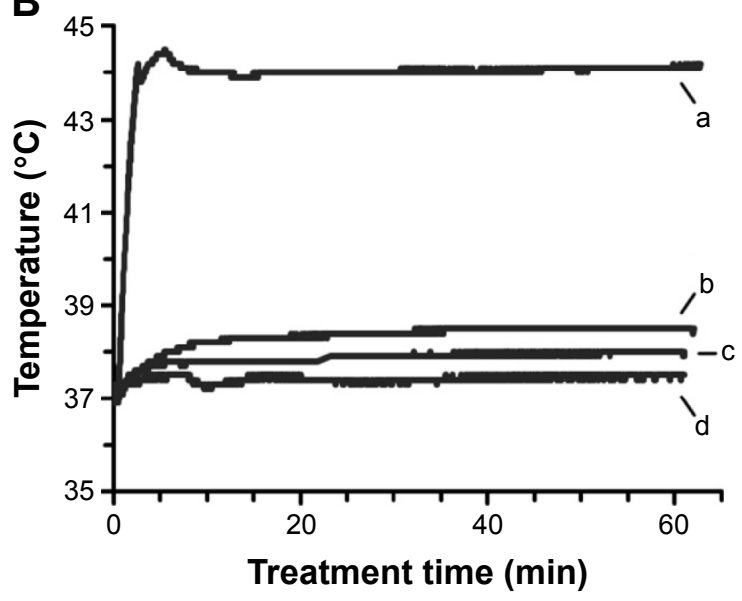

C
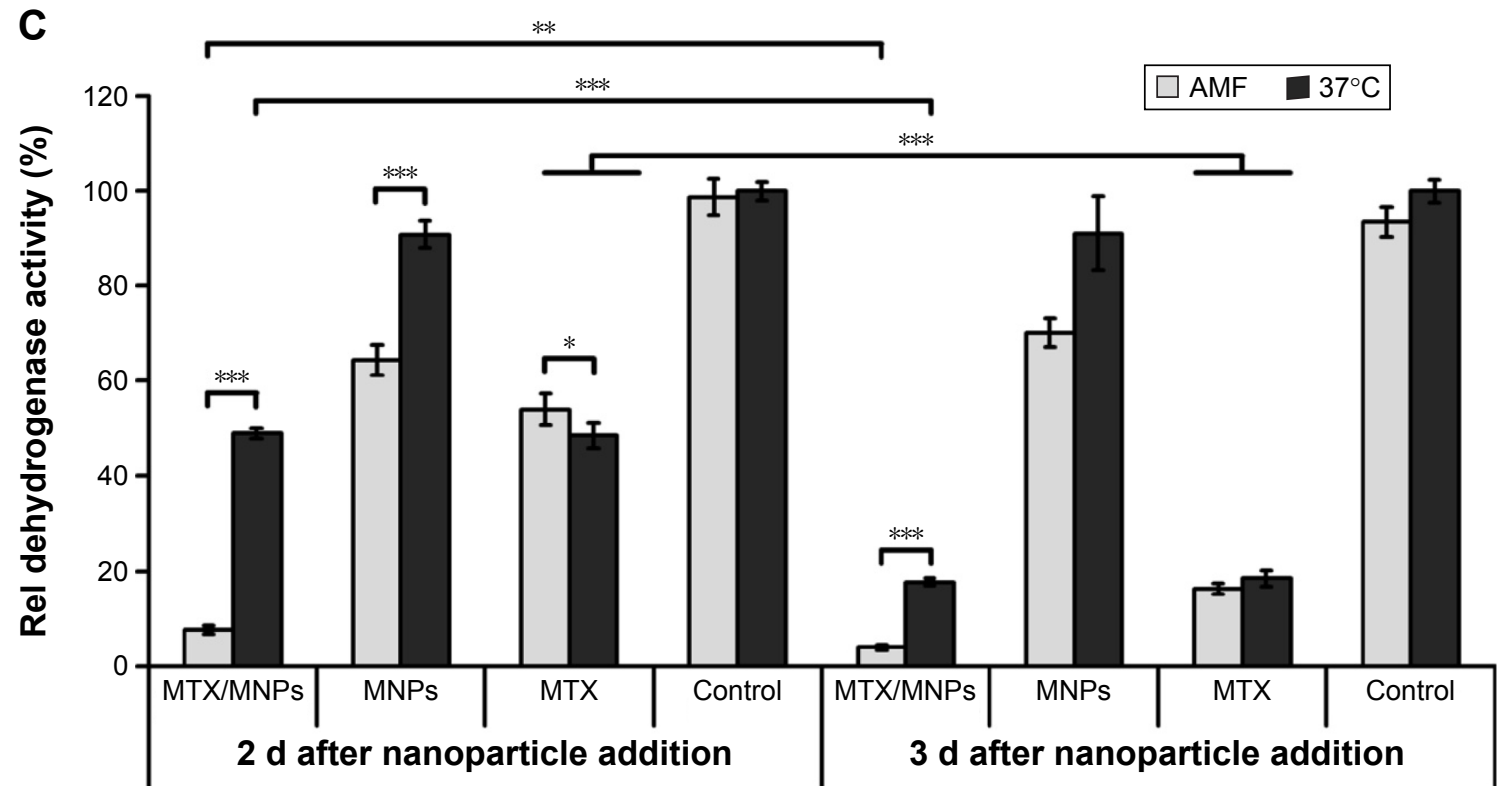

Figure 4 Increased uptake of MTX/MNPs correlated with higher temperatures and a reduced viability after in vitro hyperthermia.

Notes: (A) Representative microscopic images of the different treatment groups prior to cell harvest. (B) Representative temperature curve after magnetic heating to a target temperature of $44^{\circ} \mathrm{C}$ for $60 \mathrm{~min}$ in an AMF ( $\mathrm{H}=23.9 \mathrm{kA} / \mathrm{m}, \mathrm{f}=410 \mathrm{kHz}$ ). (a) MTX/MNPs; (b) MNPs; (c) MTX; (d) control. (C) Cellular viability as assessed by AlamarBlue ${ }^{\circledR}$ assay $(n=6)$. Throughout in vitro experiments, the following concentrations were used: MTX/MNPs, $100 \mu \mathrm{g} / \mathrm{mL} ; \mathrm{MNPs}, 100 \mu \mathrm{g} / \mathrm{mL} ; \mathrm{MTX}, 25 \mu \mathrm{g} / \mathrm{mL}$. Scale bar: $100 \mu \mathrm{m}$. Student's $t$-test showed significant differences between the groups with $* P \leq 0.05, * * P \leq 0.01$, and $* * * P \leq 0.00 \mathrm{I}$.

Abbreviations: AMF, alternating magnetic field; MNPs, magnetic nanoparticles; MTX, methotrexate.

correlating with the observed insufficiency of inhibiting tumor growth.

\section{Nanochemothermia reduces tumor} growth by interfering with a broad spectrum of proteins relevant for apoptosis, survival, angiogenesis, and

\section{cell cycle}

The application of the nanochemothermal treatment resulted in a remarkable downregulation of a broad spectrum of investigated proteins compared to the untreated controls (Figure 8). At the same time, the nanochemothermal and the thermal treatment showed a comparable protein expression pattern. Interestingly, the application of MTX/MNPs in the absence of magnetic heating led to an induction of many of the investigated proteins. At the same time, the application of MNPs per se had a protein-dependent influence on protein expression.

\section{Apoptosis}

Nanochemothermia (MTX/MNPs/AMF), generally, decreased the presence of the apoptotic proteins p-p53, p21, pro-caspase 8 , whereas pro-caspase 3 was downregulated in a time-dependent manner. Interestingly, cleaved PARP revealed an increased expression at $2 \mathrm{~h}$ posttreatment but 


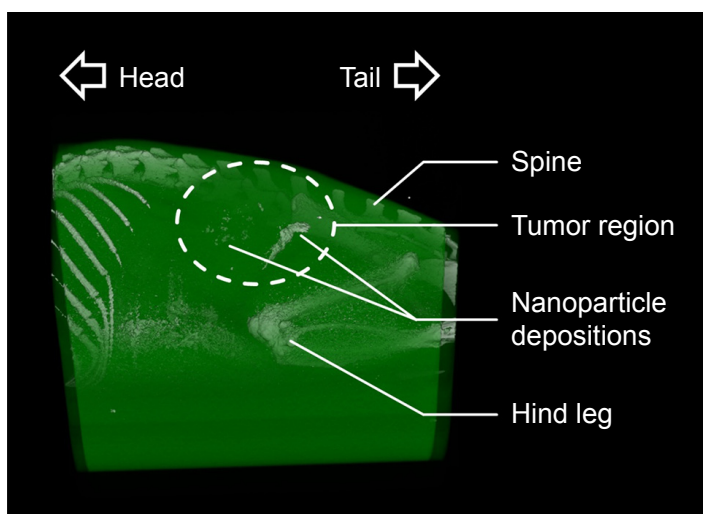

Figure 5 Micro-CT images revealed inhomogeneous intratumoral distribution of nanoparticles.

Notes: Representative micro-CT image at $24 \mathrm{~h}$ after intratumoral nanoparticle application. After reconstruction, different body parts were colored based on their $\mathrm{HU}$-values (via Imalytics software) for better visualization. The tumor area is highlighted with a dashed line.

Abbreviation: $\mathrm{CT}$, computed tomography.

also strongly decreased at later points in time. The observed destruction of proteins was assigned to the thermal treatment per se, because tumors of the thermal therapy group (MNPs/ AMF) showed an almost comparable apoptotic protein expression pattern to nanochemothermia. These effects were not encountered when treating tumors with MTX/ MNPs alone: the MTX/MNP group revealed tumors with a rather increased expression of apoptotic proteins compared to native tumors. Hereto, the presence of the MNPs per se had a minor effect, because tumors of the MNP group had an almost inconspicuous apoptotic protein expression (compared to native tumors).

\section{Cellular survival}

Nanochemothermia remarkably reduced p-ERK $1 / 2$ in a timedependent manner, whereas the Akt, BCL2, and Mcl-1 expression was (almost) abolished. Concurrently, it had only a minor effect on HSP70 but remarkably reduced HSP90. In comparison, the thermal treatment per se revealed similar effects, although a retarded reduction of $\mathrm{p}$-ERK1/2, and a time-dependent reduction of HSP70 and HSP90 were found. In contrast, MTX/MNPs had different effects on the expression of survival proteins than nanochemothermia. In this regard, p-ERK1/2, BCL2, and HSP70 were (slightly) increased in comparison to the untreated controls, whereas the expression of Akt and HSP90 remained almost unaltered. Moreover, Mcl1 was reduced and HSP70 remarkably increased. The application of MNPs alone had a heterogenic influence on the protein expression compared to the untreated control tumors with a similar expression pattern for BCL2 and HSP90, a recovering expression pattern for $\mathrm{p}-\mathrm{ERK} 1 / 2$, Akt, and Mcl-1 ${ }_{L}$, and elevated levels for HSP70.

\section{Angiogenesis}

After nanochemothermia, a time-dependent increase of the Hif- $1 \alpha$ levels was found. At the same time, the VEGF expression remained unchanged, whereas the expression levels of VEGF-R1 were slightly reduced compared to untreated tumors. Moreover, MMP2 and MMP9 levels were remarkably reduced. In comparison to nanochemothermia, the thermal treatment per se led to a fast but transient increase of Hif-1 $\alpha$. Although the effect on the expression of VEGF and VEGF-R1 was slightly more pronounced in the thermal group, both seemed to recover over time. The expression of MMP2 was remarkably reduced, whereas the MMP9 expression distinctly recovered at later points in time. The monomodal MTX/MNP group had a different expression pattern compared to the nanochemothermia group. Almost no effects on Hif- $1 \alpha$ and increased VEGF and VEGF-R1

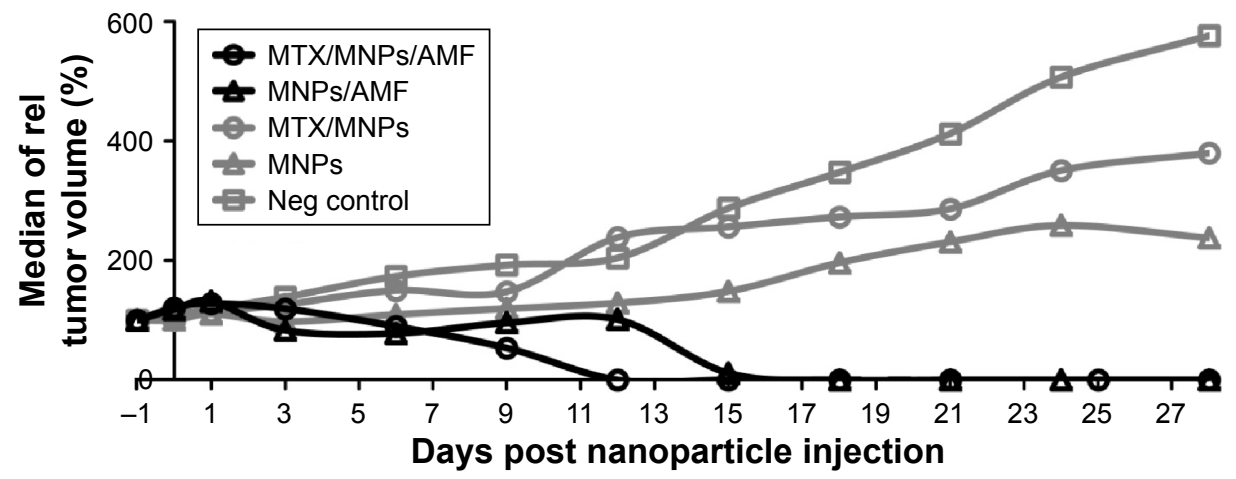

Figure 6 Fastest reduction of tumor growth after nanochemothermal treatment.

Notes: Tumor volumes $(n \geq 2)$ of each animal were normalized to the tumor volume at the day of nanoparticle injection $\left(-I \mathrm{~d}\right.$; I $\left.\mu \mathrm{g}_{\mathrm{Fe}} / \mathrm{mm}^{3} \mathrm{Tumor}\right)$ and depicted as the median of relative tumor volumes. The median CEM43T90 was slightly lower for the nanochemothermal group (I22 min) than for the thermal group (I55 min). AMF: $\mathrm{H}=23.9 \mathrm{kA} / \mathrm{m}$, $\mathrm{f}=4 \mathrm{I} 0 \mathrm{kHz}$.

Abbreviations: AMF, alternating magnetic field; MNPs, magnetic nanoparticles; MTX, methotrexate. 

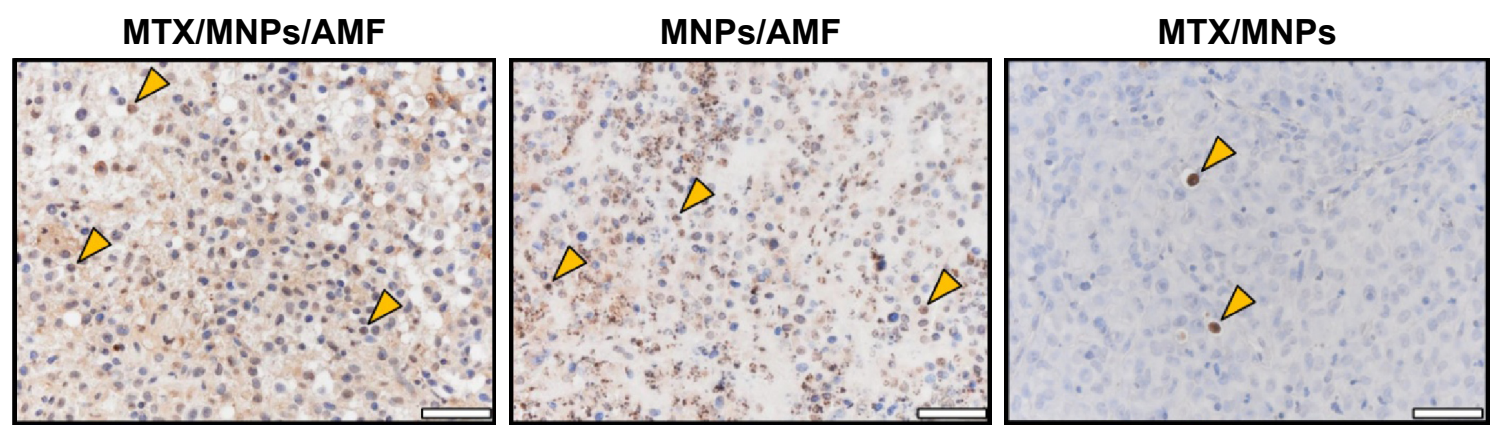

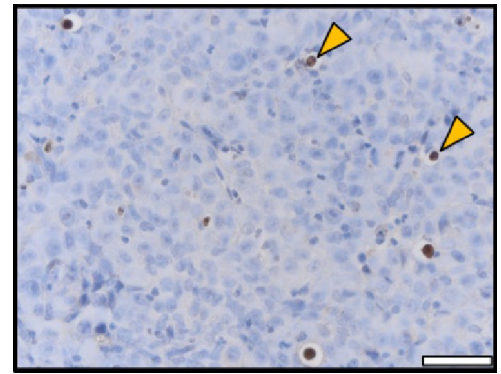

MNPs

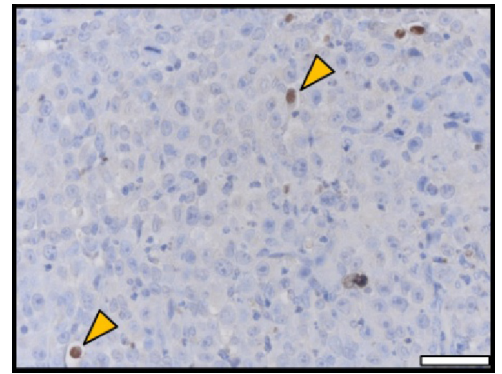

Control

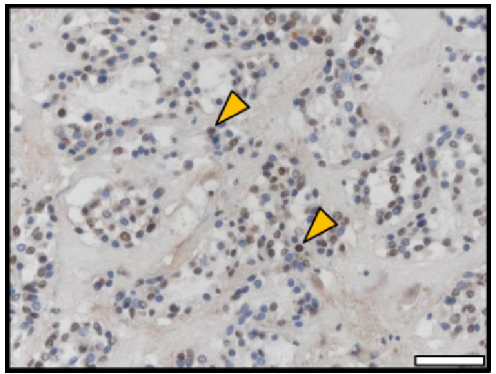

Positive control

Figure 7 Enhanced induction of apoptosis by nanochemothermia.

Notes: Representative images of tumor sections stained by TUNEL assay at $48 \mathrm{~h}$ after AMF exposure $(\mathrm{n}=3)$. Apoptotic areas are indicated by brown staining of the nuclei and cytoplasm. Representative apoptotic nuclei were marked by arrows. Throughout all in vivo experiments, nanoparticle concentrations of I $\mu \mathrm{g}_{\mathrm{Fe}} / \mathrm{mm}^{3}{ }_{\mathrm{Tumor}}$ were $\mathrm{used}_{\mathrm{f}} \mathrm{AMF}$ : $\mathrm{H}=15.4 \mathrm{kA} / \mathrm{m}, \mathrm{f}=435 \mathrm{kHz}$; positive control: DNAse I treated sections; scale bar: $50 \mu \mathrm{m}$.

Abbreviations: AMF, alternating magnetic field; MNPs, magnetic nanoparticles; MTX, methotrexate; TUNEL, transferase dUTP nick end labeling.
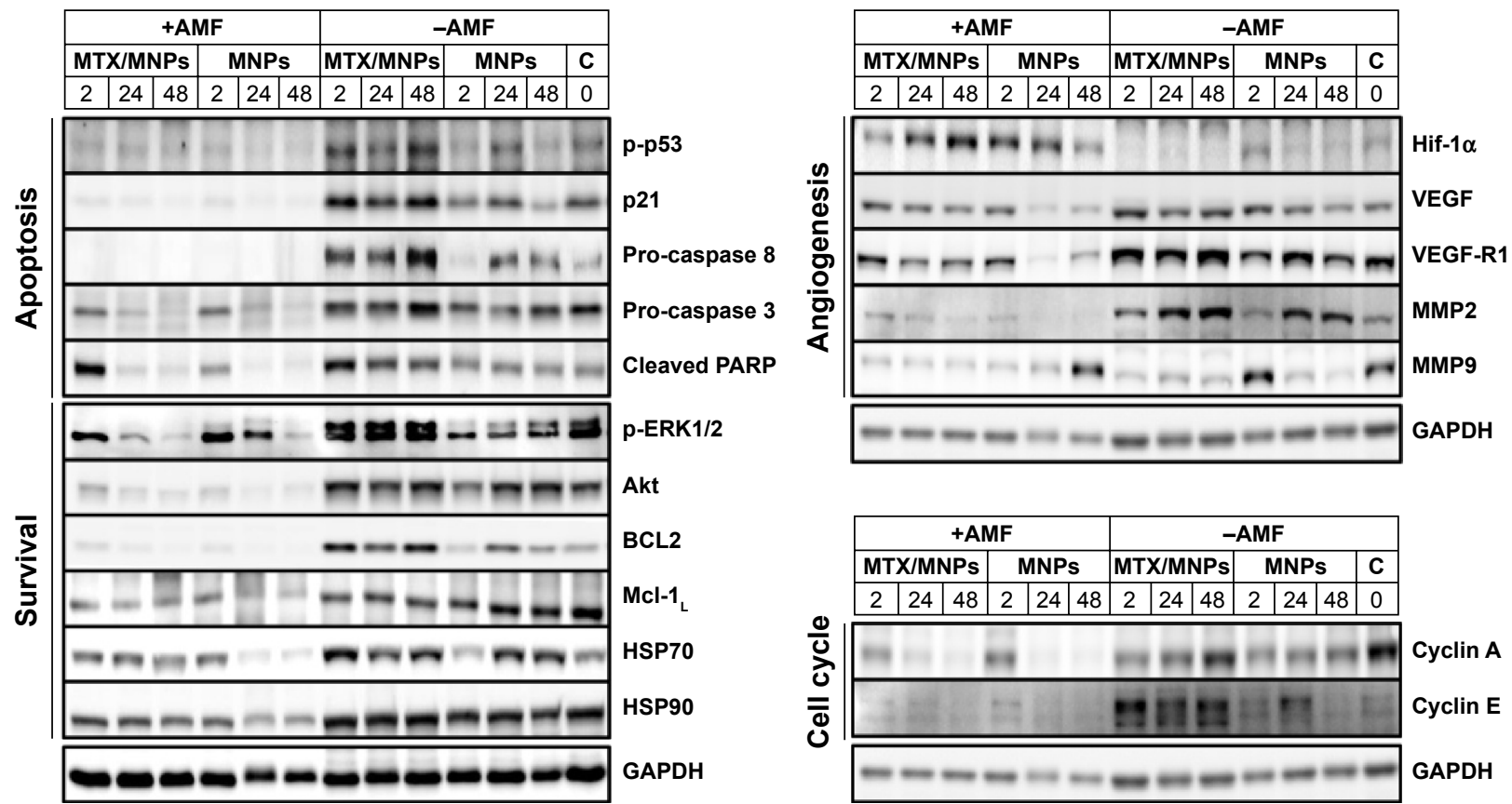

Figure 8 Treatment-dependent expression of proteins associated with cellular apoptosis and survival, angiogenesis, and cell cycle.

Notes: Representative images of at least two independent experiments. Numbers above the blot indicate the time after (theoretical) AMF exposure. Representative images for GAPDH were chosen as loading control. Throughout all in vivo experiments, nanoparticle concentrations of I $\mu \mathrm{g}_{\mathrm{Fe}} / \mathrm{mm}^{3}{ }_{\mathrm{Tumor}}$ were used. AMF: $\mathrm{H}=15.4 \mathrm{kA} / \mathrm{m}$, $\mathrm{f}=435 \mathrm{kHz}$.

Abbreviations: AMF, alternating magnetic field; C, negative control; GAPDH, glyceraldehyde 3-phosphate dehydrogenase; MNPs, magnetic nanoparticles; MTX, methotrexate; PARP, poly(ADP-ribose) polymerase; VEGF, vascular endothelial growth factor. 
levels were observed. MMP2 was remarkably upregulated in a time-dependent manner, whereas MMP9 was similar as in the nanochemothermia group. The application of MNPs alone did not distinctly change the expression of Hif-1 $\alpha$, VEGF, and VEGF-R1, but increased MMP2 and decreased MMP9 expression.

\section{Cell cycle}

The most remarkable and time-dependent downregulation of cyclin A and cyclin E was detected after nanochemothermia. An almost comparable pattern was observed for the thermal treatment. MTX/MNP treatment revealed a strong and transient reduction of cyclin $\mathrm{A}$, whereas cyclin $\mathrm{E}$ was remarkably upregulated. The presence of MNPs per se had a moderate effect on cyclin A downregulation and cyclin $\mathrm{E}$ upregulation.

\section{Discussion}

The present investigation showed the feasibility of the generated MTX/MNPs for nanochemothermal treatments based on their suitable physicochemical properties and their favorable cellular interaction. Moreover, a complete and relapse-free destruction of tumors, which was remarkably faster after the performed nanochemothermal treatment compared to the thermal treatment alone, was observed within the observation time, whereas a steady increase of the tumor volume was observed after the application of either MTX/MNPs or MNPs and the negative therapy control group. At the same time, no severe side-effects on the animal's health (eg, body weight, activity, overall appearance) were observed.

We found a remarkably increased uptake of MTX/MNPs compared to MNPs which was only MTX-functionalization dependent as the zeta potential and the hydrodynamic diameter - known to be the main defining characteristics for the fate of particles in vitro and in vivo - were almost equal for both particle formulations. Hence, we hypothesized that the MTX-dependent internalization can well be attributed to a receptor-mediated endocytosis by folate receptors, because T24 cells were reported to exhibit a high expression of these MTX-internalizing receptors due to their high metabolic and proliferative activity. ${ }^{20}$ As the uptake of native MNPs was negligible in comparison to the internalization of MTX/ MNPs, it is reasonable that the measured iron content in the MTX/MNP group must be related to an internalization of MTX/MNPs rather than to the native MNPs.

Interestingly, a comparable cytotoxicity of MTX/MNPs (without AMF) and free MTX was observed, suggesting that the coupling of MTX to the used MNPs did not negatively influence its cytotoxic potential. Moreover, these results indicated a comparable uptake of MTX/MNPs and free MTX, as MTX performs its cytotoxic action intracellularly. ${ }^{19,34}$

During the AMF exposure throughout the in vitro hyperthermia experiments, the increased uptake of MTX/ MNPs correlated with higher temperatures compared to marginally incorporated MNPs, whereas cells without any MNPs (MTX, control) were not heated. Achieving $44^{\circ} \mathrm{C}$ during in vitro experiments demonstrated the sufficiency of cellular uptake and SAR to eradicate cells with the used MTX/MNPs and field parameters.

A low MTX desorption from the particle surface was revealed by release kinetic experiments (data not shown). ${ }^{20}$ In combination with the observed high internalization of MTX/MNPs, these results point out the suitability of MTX/ MNPs for a tumor-localized nanochemothermal treatment with a low MTX diffusion after intratumoral MTX/MNP application, resulting in a minimization of cellular adaptability toward emerging cellular stress. For a systemic application, $\sim 500 \mathrm{mg} / \mathrm{m}^{2}$ MTX is administered intravenously. ${ }^{35}$ In contrast, only $\sim 22 \mathrm{mg} / \mathrm{m}^{2}$ MTX is used within our study and applied directly to the tumor region. Therefore, a high biosafety is expected and the systemic burden is hypothesized to be considerably lower after the utilization of MTX/MNPs. Moreover, especially nanoparticles with a hydrodynamic diameter $>200 \mathrm{~nm}$ that reach the systemic circulation are known to be cleared rapidly from the bloodstream by the MPS (predominantly by the liver and spleen) and metabolized afterward. ${ }^{36}$ Although the metabolization of nanoparticles is not fully understood, particularly iron oxide nanoparticles are expectedly degraded in late endosomes/lysosomes to atomic iron and used for cellular processes (eg, Fenton reaction). ${ }^{37}$

\section{Nanochemothermia inhibits tumor growth by regulating key proteins of apoptosis, cellular survival, angiogenesis, and cell cycle}

The superiority of the preformed nanochemothermia compared to the thermal treatment manifested in the fastest (and relapse-free) destruction of tumors at lower CEM43T90 values. This higher therapy efficiency at lower treatment temperatures is especially advantageous in tumor areas where the target temperature cannot be homogeneously achieved due to an inhomogeneous distribution of the applied MTX/ MNPs. With regard to the amount of nanoparticles needed 
to achieve a defined temperature increase in tumors, both density and distribution are important. More detailed studies are needed to further clarify this aspect. Moreover, a tumorlocalized persistence (up to $28 \mathrm{~d}$ ) of applied MTX/MNPs was observed by immunohistochemistry (Figure S2), allowing a continuous and localized chemotherapy by the MNP-bound MTX, fostering tumor destruction in the nanochemothermia group. TUNEL assays revealed a remarkable increase of apoptotic cells after the nanochemothermal treatment in comparison to the thermal treatment alone. It is worth mentioning that a diffuse TUNEL-positive staining of the cytoplasm was only present after heating in AMF-treated tumors, reflecting an additional labeling of remarkably fragmented RNA (likely by the applied heat) due to the labeling of $3^{\prime}-\mathrm{OH}$ termini after the breakage of nucleic acids. ${ }^{38}$ The sole AMF treatment has no impact on therapy outcome as it does not result in the unspecific heating of tissue, in particular, because much lower magnetic field amplitudes and frequencies are used compared to MRI. By reaching temperatures up to $50^{\circ} \mathrm{C}$ during the performed in vivo experiments, the observed remarkable tumor destruction in both heat-based treatments was hypothesized to be connected to the regulation and/or destruction of key proteins involved in apoptosis, cell survival, angiogenesis, and cell cycle. At the same time, tumor vasculature was highly likely destructed leading to an impaired supply of the tumor with nutrition (eg, oxygen).

\section{Impairment of apoptotic signaling}

The presented data of active (phosphorylated) p53 (p-p53) reveled its marginal impact on the superior reduction of tumor volumes of the nanochemothermal treatment compared to the thermal treatment itself. Due to a mutation of p53 (in-frame deletion at Tyr126) in T24 cells, p53 is only expressed at low levels and mainly in its active state. ${ }^{38-40}$ Hence, only a low expression of p-p53 was observed in the treatment group and in the control groups, whereas unphosphorylated (inactive) p53 was abundant in any group. We hypothesized, that the destruction of the mutated p53 contributed to tumor destruction in the nanochemothermal and the thermal group, because p53-deficient cells were reported to undergo a transient cell cycle arrest followed by apoptosis or mitotic catastrophe..$^{2,41-43}$ Furthermore, both treatments have the capability to reduce the p53 mutation-based insensitivity of T24 cells toward radiation and the frequent tumor relapse and poor prognosis in bladder cancer. In contrast, the observed slightly higher p-p53 level after MTX/MNP treatment can be explained by the capability of MTX to induce p53 signaling, but confirmed the insufficiency of MTX as monomodal therapy to reduce tumor growth. ${ }^{22}$
Like p53, p21 did not contribute to the superior efficacy of nanochemothermia compared to the thermal therapy, as a similar, only heat-dependent reduction of protein expression was detected for both groups. Although the reported induction of $\mathrm{p} 21$ by MTX could be confirmed (MTX/MNP group), only marginal levels of p21 were detectable after nanochemothermal and thermal treatment, indicating a heatdependent destruction of $\mathrm{p} 21$ or its precursor $\mathrm{p} 53 .{ }^{22,44,45}$ As the tumor suppressive ability of p21 is mainly assigned to a cell cycle arrest, an impairment or destruction of p21 may hinder cellular growth arrest and senescence. ${ }^{44-47}$ Nevertheless, p21 signaling of T24 cells is already impaired (also due to mutated p53) and its cytosolic accumulation was connected to cell cycle progression and cell growth, indicating an oncogenic action of $\mathrm{p} 21 .^{48-50}$ Though a destruction of $\mathrm{p} 21$ is not preferential, the destruction of overexpressed $\mathrm{p} 21$ or impaired p21 signaling may contributed to tumor therapy and probably accounted to the remarkable tumor destruction after the nanochemothermal and thermal treatment. Again, the MTXdependent induction of p21 in the MTX/MNP group did not manifest in remarkable tumor destruction, demonstrating the insufficiency of MTX as monomodal cancer treatment.

No major contribution of pro-caspase 8 (precursor of initiator caspase 8) on the enhanced tumor destruction of the nanochemothermal treatment compared to the thermal treatment could be detected as no pro-caspase 8 expression was observed for both groups. As a fast and strong increase of pro-caspase 8 in the MTX/MNP group was observed (whereas MNPs alone had no influence), the absence of procaspase 8 can rather be attributed to its heat-based destruction than to its cleavage to active caspase 8 .

At the same time, reduced levels of pro-caspase 3 (precursor of executioner/initiator caspase 3) were also observed after the nanochemothermal and the thermal treatment of tumors, indicating no distinct contribution of this enzyme to the superior destruction of tumors of the first mentioned group. Moreover, MTX/MNPs (and MNPs) did not remarkably influence the expression of pro-caspase 3 and were almost comparable to untreated control, suggesting a heat-dependent destruction of pro-caspase 3.

Our data on the expression of both pro-caspases indicated that apoptosis might well be executed at very early points in time in the nanochemothermal and the thermal group through the intrinsic pathway (eg, caspase 9, caspase 3) in response to cellular stress. The reduced (but not abundant) pro-caspase 3 level suggests a cleavage of pro-caspase 3 to caspase 3 with a concurrent absence of caspase 8 . It is worth mentioning that an overexpression of pro-caspases 
has been associated with several types of cancer, including renal, breast, and lung cancer, as under apoptotic conditions pro-caspases are cleaved to active (cleaved-) caspases. ${ }^{51}$ In these cases, their downregulation/destruction via nanochemothermia may be beneficial as cancer therapy. Although a reduced level of pro-caspases is thought to correlate with an increase of functionally active caspases, their reduced presence may be caused by the destruction/denaturation of proteins due to the applied heat rather than their activation.

Interestingly, higher levels of cleaved PARP at $2 \mathrm{~h}$ posttreatment were found in the nanochemothermia group, corresponding to its superior feasibility to inactivate tumors. Generally, the expression pattern of cleaved PARP is genuine, because 1) it corresponded to the pattern observed for procaspase 3 and 2) the effector caspase 3 has a central but not exclusive role in the apoptotic processing as it is primarily responsible for PARP-cleavage during apoptosis..$^{52,53}$ In this regard, the reduced pro-caspase 3 level at $2 \mathrm{~h}$ after chemothermia (compared to the untreated control) most likely indicated the conversion into (active) caspase 3, resulting in an increased PARP cleavage.

It is worth mentioning that the levels of cleaved PARP were remarkably reduced in a time-dependent manner after the nanochemothermal and the thermal treatment, in contrast with the results of the TUNEL assay at $48 \mathrm{~h}$. One possible explanation for this observation may be related to the heatdependent induction of DNA damage and the concomitant destruction of proteins involved in DNA repair (eg, PARP). Hence, the cells were not able to repair the induced DNA damage, leading to an endured positive TUNEL staining with a concomitant absence of PARP (and therefore cPARP).

Based on the higher cytotoxicity of MTX/MNPs (MTX/ MNP group), the higher cleaved PARP levels after nanochemothermia in comparison to thermal treatment alone were not surprising. Moreover, the observed tumor growth in the MTX/MNP group confirmed (again) the insufficiency of this treatment in reducing tumor growth.

Taken together, the presented expression data of proapoptotic and tumor suppressive proteins suggested that especially the increase of cleaved PARP after the nanochemothermal treatment manifested in a higher reduction of the tumor volume at later points in time in this particular group. Nonetheless, the presence of concomitant processes, such as necrosis and mitotic catastrophe, most likely supported the observed tumor destructive effect. Although the utilization of MTX/ MNPs as monovalent treatment was shown to induce a variety of proapoptotic signaling pathways, it was insufficient to remarkably reduce tumor growth.

\section{Impairment of cellular survival signaling}

Concerning the investigated proteins that are involved in cellular survival, especially the serine/threonine protein kinase p-ERK1/2 was found to be most remarkably downregulated after nanochemothermia and correlated with the superior therapy efficacy compared to the thermal treatment. As the expression of ERK1/2 is associated with crucial cellular programs, including proliferation, differentiation, motility, and cell death as well as the suppression of caspase cascades (independent of p53 signaling) and the enhancement of the transcriptional activity of angiogenic Hif- $1 \alpha$, its impairment is suggested to be particularly important in cancer treatments. ${ }^{54,55}$ Particularly p-Erk2 was remarkably downregulated after nanochemothermal treatment. We hypothesize that $\mathrm{p}$-Erk2 reduction contributed to the better outcome of nanochemothermia as Erk2 has been described to be associated with cellular proliferation. ${ }^{56}$

In contrast, no influence on the observed increased tumor destruction of the nanochemothermal compared to the thermal treatment could be assigned to the serine/threonine kinase p-Akt, as it was almost equally downregulated after both treatments. Subsequently, it was comparable to the untreated negative control in the absence of heat (MTX/MNPs and MNPs) indicating a heat-dependent impairment of p-Akt. As part of PI3K signaling, Akt is a regulator of a variety of critical steps including cell survival, growth, proliferation, and migration and is altered at high frequency in bladder cancer. ${ }^{57-60}$ Furthermore, Akt is crucial in VEGF-mediated angiogenesis. ${ }^{61-63}$ Although it was reported that a single-agent targeted PI3K cancer therapy may not be successful, we could successfully show the ability of nanochemothermia to remarkably downregulate Akt signaling and display its feasibility as a beneficial tool in cancer treatment. ${ }^{57}$

Comparable to p-Akt, BCL2 was found equally downregulated after nanochemothermia and the thermal treatment. Therefore, this protein also did not contribute to the observed superior tumor destruction after nanochemothermal treatment. Although BCL2 can be activated by Akt and/or Erk1/2 signaling, the remarkable downregulation and the comparable expression pattern after the application of heat were assigned rather to a direct heat-dependent destruction of BCL2 than to the observed expression pattern of Akt and Erk1/2. As an overexpression of oncogenic BCL2 has been associated with numerous cancers including melanoma, breast, prostate, lung, and leukemia, we hypothesized that the heat-based decrease of BCL2 levels indicates an impaired cellular survival and most likely contributed to the destruction of T24 bladder tumors. ${ }^{64,65}$ 
The expression of $\mathrm{Mcl}_{\mathrm{L}}$, the long isoform of Mcl-1, was remarkably downregulated after heating, and therefore, did not contribute to the superior tumor destruction of the nanochemothermal compared to the thermal therapy. Due to its ability to inhibit apoptosis and enhance cellular survival, elevated Mcl- $1_{L}$ levels contribute to chemoresistance and are associated with poor prognosis in oral cancer ${ }^{66,67}$ Nanochemothermia and thermal treatment led to a reduction of Mcl- $1_{\mathrm{L}}$ by a direct and heat-mediated destruction of $\mathrm{Mcl}_{\mathrm{L}} \mathrm{L}_{\mathrm{L}}$ and/or by the knockdown of Akt-signaling, and therefore, retaliate tumor growth by reducing cellular survival. Although MTX/MNPs were able to slightly reduce $\mathrm{Mcl}-1_{\mathrm{L}}$ signaling, its reduced expression did not manifest in a remarkably reduced tumor growth.

A comparable HSP70 expression after magnetic heating and the untreated negative control was observed, indicating only a minor impact on the enhanced performance of the nanochemothermal compared to the thermal treatment. Although this finding was in accordance with an earlier publication analyzing the HSP70 expression at $2 \mathrm{~h}$ after the short-term application of magnetic heating, this study demonstrated the persistence of HSP70 levels up to 48 h. ${ }^{17}$ Due to its chaperon function, HSP70 was reported to be upregulated upon cellular stress as caused by heat or toxic stimuli. ${ }^{68,69}$ Therefore, the instant elevation of HSP70 in the MTX/MNP group and the time-dependent upregulation in the MNP group were hypothesized to be based on the application of MTX/MNPs or MNPs which probably were recognized as toxic stimuli. This assumption was additionally confirmed by the fact that the application of higher cytotoxic MTX/MNPs caused a faster increase of HSP70. These observations exemplify the insufficiency of the utilization of MTX/MNPs as monomodal cancer treatment, correlating with the observed tumor progression. Interestingly, the remarkable upregulation of HSP70 after MTX/MNP and MNP treatment was prevented by magnetic heating. We concluded that, in contrast to MTX/ MNPs, both heat-based treatments (nanochemothermia and thermal treatment) were able to reduce the HSP70 level to the level of the untreated control, and therefore, supported tumor destruction by preventing the stabilization or expression of tumor-associated proteins and the apoptosome formation.

For HSP90, a comparable downregulation after nanochemothermia and thermal treatment was found, indicating no impact of HSP90 on the superior tumor destruction of the aforementioned treatment regime. Moreover, neither the application of MTX/MNPs nor MNPs influenced HSP90 expression. We, therefore, conclude that the applied temperatures were sufficient to destroy HSP90 and that they successfully prevented the HSP90-related protein stabilization. By this, antiapoptotic proteins were also destroyed, resulting in a decreased cellular survival. In addition, we hypothesized a heat-based reduction of tumor growth related to a remarkable impairment of the vascular tone and consequently a deficiency of tumor nutrition. HSP90 is reported as binding partner and scaffolding protein involved in the activation of endothelial nitric oxide synthase by Akt after VEGF stimulation, and therefore, has protective function in the cardiovascular system. ${ }^{62,70}$

Taken together, the presented results of key proteins involved with tumor cell survival clearly demonstrated their heat-based impairment and destruction, whereas especially the impairment of p-Erk1/2 seems to be responsible for the superior outcome of the performed nanochemothermal treatment compared to the thermal treatment alone. Interestingly, the applied MTX/MNPs partly led to a strong induction of survival signaling, manifesting in tumor growth rather than its destruction.

\section{Impairment of angiogenic signaling}

We observed a superior tumor destruction of the nanochemothermia compared to the thermal treatment with increasing Hif- $1 \alpha$ levels after the first mentioned and decreasing Hif- $1 \alpha$ levels after the latter mentioned treatment. As both modalities differ only in the utilization of MTX/MNPs instead of MNPs, this effect was associated to the combined application of MTX and magnetic heat.

Hif- $1 \alpha$ is a crucial regulator of cellular developmental response to hypoxia, and therefore, heavily implicated in cancer biology, due to its involvement in vascularization and angiogenesis, energy metabolism, cell survival, and tumor invasion..$^{55,71-76}$ Based on the assumption that elevated Hif- $1 \alpha$ levels correlate with an elevated tumoral hypoxia, we prognosed a stronger (and longer-lasting) destruction of blood vessels after nanochemothermia compared to thermal treatment.

Interestingly, the expression of downstream targets, involved in the formation of new blood vessels (eg, Erk1/2, VEGF, and MMPs), was not found to be increased, demonstrating the feasibility of nanochemothermia to successfully prevent proangiogenic signaling and inhibit tumor growth.

In this context, the expression of VEGF after nanochemothermia and the thermal treatment was comparable to the untreated control and therefore not responsible for the enhanced tumor destruction of the combinatory nanochemothermal treatment regime. As VEGF expression is associated with a poor prognosis in different cancers (eg, bladder and breast) and increases with an advanced 
pathologic stage in bladder cancer, VEGF and its receptors are important targets in cancer therapies (eg, bevacizumab, sunitinib, and sorafinib) ${ }^{77}$ In this regard, nanochemothermia prevented the Hif-1 $\alpha$-dependent upregulation of VEGF and therefore presumably led to a shortage of tumor nutrition and a destruction of the tumor, although it was not able to abolish VEGF expression.

Like VEGF, the data of VEGF-R1 expression revealed no indication for the superior outcome of nanochemothermia in comparison to the applied thermal treatment, since a comparable and time-dependent downregulation and/or destruction of VEGF-R1 was observed for both treatments. As the VEGF-R1 is involved in critical signaling pathways in endothelial cells, vascular development, and hematopoiesis, a reduction of VEGF-R1 was reported to lead to the formation of abnormal and nonfunctional vessels. ${ }^{78-81}$ Therefore, an inhibition of this receptor is suggested as suitable target in tumor therapy. Nevertheless, several clinical trials and xenograft models described a resistance to antiangiogenic therapies. ${ }^{82-84}$ We found a slight upregulation of VEGF-R1 in the MTX/MNP group, indicating the insufficiency of this treatment to impair VEGF-R1 expression and inhibit tumor growth. In contrast, our results clearly revealed a downregulation of the VEGF-R1 expression, demonstrating the great potential of the performed nanochemothermal treatment to impair VEGF-R1-dependent angiogenic signaling and inhibit tumor growth independent of the expression of Hif- $1 \alpha$.

Within the present investigation, we found a comparable downregulation of MMP2 after nanochemothermia and thermal therapy, whereas a remarkable and time-dependent induction was observed after MTX/MNP treatment. Therefore, MMP2 was not responsible for the preferential tumor destruction of the nanochemothermal therapy compared to the thermal treatment. Nevertheless, its reduction after both heat treatments contributed to tumor destruction, whereas its upregulation after MTX/MNP treatment is rather detrimental and supported tumorigenesis.

In contrast to MMP2, the MMP9 protein expression contributed to the observed superior tumor destruction after the chemothermal treatment, as its expression was remarkably downregulated after nanochemothermia, but recovered after the thermal treatment over time. Although the MMP9 level was distinctly reduced in the MTX/MNP group to levels of the nanochemothermal and thermal treatment groups, the application of MTX/MNPs alone did not remarkably inhibit tumor growth.

Interestingly, MMPs have, generally, been described as suitable targets in cancer treatments due to an involvement in central tumor-associated processes including angiogenesis (eg, mobilization of VEGF), apoptosis, proliferation, invasion, and metastasis, but performed poorly in clinical trials and have shown a high toxicity. ${ }^{85-90}$ Here, we could show the capability of nanochemothermia to remarkably downregulate MMP2 and MMP9 in a tumor-localized manner with a minimal influence on animal's health (weight, blood count).

Based on the presented results, we could clearly demonstrate the suitability of the performed nanochemothermal therapy for the destruction/regulation of key proteins involved in angiogenic signaling and metastasis, as elevated Hif- $1 \alpha$ levels suggested an increased destruction of tumor vasculature (hypoxic regions) with a subsequent inhibition of proangiogenic proteins and prometastatic proteins. The applied MTX/MNPs alone were highly likely insufficient to inhibit angiogenic and metastatic proteins, manifesting in an impaired suppression of tumor growth.

\section{Impairment of cell cycle progression}

The superior outcome of tumor reduction after the nanochemothermal treatment compared to the thermal treatment alone likely resulted from the higher reduction of cyclin $\mathrm{A}$ after nanochemothermia, as cyclin $A$ is involved in $\mathrm{G} 2 / \mathrm{M}$ transition and its absence suggested a G2 block of the cell cycle. Interestingly, the application of MTX/MNPs initially reduced the cyclin A levels to the same extent but recovered over time, revealing the insufficiency of this monomodal treatment to successfully hinder cell cycle progression. In contrast, high cyclin A levels of untreated negative control tumors indicated a fast G2/M transition, leading to the accumulation of cells in the $\mathrm{M}$ phase, and confirmed the high proliferative activity of T24 tumors.

Cyclin E (G1/S transition) was more strongly decreased after nanochemothermia than by the thermal treatment, contributing the observed superior tumor destruction after the first mentioned treatment. The utilization of MTX/MNPs alone strongly induced the expression of cyclin E, and therefore, rather supported tumor formation and proliferation.

As T24 tumors are highly proliferative, the combination of the observed high cyclin A (G2/M transition) expression and low cyclin E (G1/S transition) levels suggested the accumulation of the majority of cells in $M$ rather than $S$ phase of the cell cycle. In this regard, it was reported that an overexpression of either cyclin A or cyclin E results in a decrease of $\mathrm{G} 1$ cells in a cycling cell population, and that elevated levels of cyclin E were associated with an increased cell proliferation in a variety of cancer types including bladder, breast, and colon..$^{45,91,92}$ The combined 
reduction of cyclin A and cyclin E levels, especially by nanochemothermia, suggested an impairment of the cell cycle at multiple phases resulting in a G1 and/or G2 block, and therefore, contributed to tumor destruction and the preferential outcome of this treatment. In contrast, the application of MTX/MNPs seemed to stimulate cell cycle progression, and therefore, contributed to proliferation and tumor growth. Although the observed reduced tumor destructive effect of MTX/MNPs in comparison to MNPs is not fully explainable, protein analyses suggested a more unfavorable expression pattern (eg, elevated p-ERK1/2, BCL-2, VEGF, and MMP2) after MTX/MNP treatment, resulting in a progression of cell cycle as indicated, for example, by cyclin A.

\section{Prospect}

With consideration of the clinical situation, the generated MTX/MNPs could prospectively be endoscopically applied into the tumor area of the bladder before the transurethral resection of bladder tumors (TURBTs) and heated by the utilization of a small AMF inductor (eg, minimal-invasively). By this additional nanochemothermal approach, tumor areas that would have been not completely removed (and overlooked) by TURBT (because TURBT exhibits the risk of understaging tumors and a high risk of residual tumor) can be treated long-lasting and repeatedly with nanochemothermia. ${ }^{93}$ In contrast to "only" physically removing the tumor by TURBT, the application of nanochemothermia impairs the expression of fundamental tumor proteins (eg, with implications in angiogenesis). Therefore, nanochemothermia provides a huge potential during the treatment of bladder cancer as nanochemothermia can additionally be performed in order to induce apoptosis and impair angiogenesis, before "physical" removal of the tumor by TURBT. Hence, the nanochemothermal treatment may increase the efficiency of TURB.

\section{Conclusion}

The present investigation clearly demonstrates the superior potential of nanochemotherapy over the monomodal thermal treatment. It led to a localized and relapse-free destruction of T24 bladder tumors with a high biocompatibility as indicated by the animal's body weight, activity, and overall appearance. The superior effect of nanochemothermia was specially attributed to an increased uptake of MTX/MNPs into tumor cells and an impairment of proapoptotic signaling (eg, p53, p21), cell survival (eg, pERK1/2), and cell cycle (eg, cyclin) pathways, and to the distinct effects of heat shock proteins (eg, HSP70, HSP90) after exposure to heating. With regard to angiogenesis, nanochemothermia decreased, for example, VEGF-R1 and MMP9 more sustainably than the thermal treatment alone, although elevated Hif- $1 \alpha$ levels indicated an enhanced and longer lasting tumor hypoxia in the case of the nanochemothermal treatment. Based on the complex experimental approach, the presence of processes, such as necrosis (eg, due to high temperatures and an impaired tumor nutrition) and mitotic catastrophe (eg, by the impairment of p53) most likely supported the observed tumor destructive effect. Interestingly, the utilization of MTX/MNPs as a monomodal therapy regimen was insufficient to reliably destroy tumors. Though the limited tumor reductive effect of MTX/MNPs in comparison to MNPs cannot fully be explained, protein analyses suggest that the cells are still able to proliferate after MTX/ MNP treatment. The presented results clearly demonstrate that the combined utilization of smart nanomaterials, such as MTX/MNPs and magnetic heat - as it has been used in our nanochemothermia modality - can distinctly help in winning the fight against cancer.

\section{Acknowledgments}

The present investigation was carried out within the projects "PAK-151" (HI-689/7-4), which is funded by the Deutsche Forschungsgemeinschaft, and "Multifunctional Nanoparticles for the Selective Detection and Treatment of Cancer" (MultiFun), which is funded by the European Seventh Framework Program (FP7/2007-2013) under grant agreement no 262943. We acknowledge Y Ozegowski, S Burgold, and especially J Göring for the valuable technical assistance provided. We further thank Dr F Tansi for proofreading the manuscript. MS is the main author of this manuscript. MS was additionally supported by the Graduate Academy of the Friedrich Schiller University, Jena.

\section{Disclosure}

The authors report no conflicts of interest in this work.

\section{References}

1. Schenk-Braat EA, Bangma $\mathrm{CH}$. Immunotherapy for superficial bladder cancer. Cancer Immunol Immunother. 2005;54(5):414-423.

2. Hinata N, Shirakawa T, Zhang Z, et al. Radiation induces p53-dependent cell apoptosis in bladder cancer cells with wild-type-p53 but not in p53-mutated bladder cancer cells. Urol Res. 2003;31(6):387-396.

3. Rampersaud EN, Vujaskovic Z, Inman BA. Hyperthermia as a treatment for bladder cancer. Oncology (Williston Park). 2010;24(12): 1149-1155.

4. Issels RD. Hyperthermia adds to chemotherapy. Eur J Cancer. 2008; 44(17):2546-2554. 
5. Hildebrandt $\mathrm{B}$, Wust $\mathrm{P}$, Ahlers $\mathrm{O}$, et al. The cellular and molecular basis of hyperthermia. Crit Rev Oncol Hematol. 2002;43(1):33-56.

6. Zheng M, Yue C, Gong P, et al. Single-step assembly of DOX/ICG loaded lipid A polymer nanoparticles for highly effective chemophotothermal. ACS Nano. 2013;7(3):2056-2067.

7. Zhao P, Zheng M, Luo Z, et al. NIR-driven smart theranostic nanomedicine for on-demand drug release and synergistic antitumour therapy. Sci Rep. 2015;5:14258.

8. Hilger I, Andrä W, Hergt R, Hiergeist R. Electromagnetic heating of breast tumors in interventional radiology: in vitro and in vivo studies in human cadavers and mice. 2001;218(2):570.

9. Hilger I, Hergt R, Kaiser WA. Towards breast cancer treatment by magnetic heating. J Magn Magn Mater. 2005;293(1):314-319.

10. Kossatz S, Ludwig R, Dähring H, et al. High therapeutic efficiency of magnetic hyperthermia in xenograft models achieved with moderate temperature dosages in the tumor area. Pharm Res. 2014;31(12): 3274-3288.

11. Ludwig R, Stapf M, Dutz S, Müller R, Teichgräber U, Hilger I. Structural properties of magnetic nanoparticles determine their heating behavior - an estimation of the in vivo heating potential. Nanoscale Res Lett. 2014;9(1):602.

12. Dewey WC. Arrhenius relationships from the molecule and cell to the clinic. Int J Hyperthermia. 2009;25(1):3-20.

13. Purschke M, Laubach HJ, Anderson RR, Manstein D. Thermal injury causes DNA damage and lethality in unheated surrounding cells: active thermal bystander effect. J. Invest. Dermatol. 2010;130(1):86-92.

14. Franke K, Kettering M, Lange K, Kaiser WA, Hilger I. The exposure of cancer cells to hyperthermia, iron oxide nanoparticles, and mitomycin C influences membrane multidrug resistance protein expression levels. Int J Nanomedicine. 2013;8:351-363.

15. Hilger I, Rapp A, Greulich KO, Kaiser WA. Assessment of DNA damage in target tumor cells after thermoablation in mice. Radiology. 2005;237(2):500-506.

16. Hilger I, Hiergeist R, Hergt R, Winnefeld K, Schubert H, Kaiser WA. Thermal ablation of tumors using magnetic nanoparticles: an in vivo feasibility study. Invest Radiol. 2002;37(10):580-586.

17. Stapf M, Pömpner N, Kettering M, Hilger I. Magnetic thermoablation stimuli alter BCL2 and FGF-R1 but not HSP70 expression profiles in BT474 breast tumors. Int J Nanomedicine. 2015;10(10):1931-1939.

18. Zakaria MB, Belik AA, Liu CH, et al. Prussian blue derived nanoporous iron oxides as anticancer drug carriers for magnetic-guided chemotherapy. Chem Asian J. 2015;10(7):1457-1462.

19. Chan ESL, Cronstein BN. Mechanisms of action of methotrexate. Bull NYU Hosp Joint Dis. 2013;71(Suppl 1):5-8.

20. Stapf M, Pömpner N, Teichgräber U, Hilger I. Heterogeneous response of different tumor cell lines to methotrexate-coupled nanoparticles in presence of hyperthermia. Int J Nanomedicine. 2016;11:485-500.

21. Kettering $M$, Richter $\mathrm{H}$, Wiekhorst $\mathrm{F}$, et al. Minimal-invasive magnetic heating of tumors does not alter intra-tumoral nanoparticle accumulation, allowing for repeated therapy sessions: an in vivo study in mice. Nanotechnology. 2011;22(50):505102.

22. Spurlock CF 3rd, Tossberg JT, Fuchs HA, Olsen NJ, Aune TM. Methotrexate increases expression of cell cycle checkpoint genes via JNK activation. Arthritis Rheum. 2012;64(6):1780-1789.

23. Goncharova SA, Frankfurt OS. Effect of methotrexate on the cell cycle of L1210 leukemia. Cell Tissue Kinet. 1976;9(4):333-340.

24. Lim CU, Zhang Y, Fox MH. Cell cycle dependent apoptosis and cell cycle blocks induced by hyperthermia in HL-60 cells. Int J Hyperthermia. 2006;22(1):77-91.

25. Coss RA, Dewey WC, Bamburg JR. Effects of hyperthermia on dividing Chinese hamster ovary cells and on microtubules in vitro. Cancer Res. 1982;42(3):1059-1071.

26. Bhuyan BK. Kinetics of cell kill by hyperthermia. Cancer Res. 1979; 39(6 Pt 2):2277-2284

27. Mindell JA. Lysosomal acidification mechanisms. Ann Rev Physiol. 2012;74(1):69-86.
28. Teran FJ, Casado C, Mikuszeit N, et al. Accurate determination of the specific absorption rate in superparamagnetic nanoparticles under non-adiabatic conditions. Appl Phys Lett. 2012;101(6):062413.

29. Dutz S, Kettering M, Hilger I, Müller R, Zeisberger M. Magnetic multicore nanoparticles for hyperthermia - influence of particle immobilization in tumour tissue on magnetic properties. Nanotechnology. 2011; 22(26):265102.

30. Gleichmar C. Untersuchung des Einflusses der Umgebung auf die Eigenschaften magnetischer Nanoteilchen [Investigation of the influence of the environment on the properties of magnetic nanoparticles] [bachelor's thesis]. Jena: University of Applied Sciences Jena; 2009. German.

31. Ohta M, Handa A, Iwata H, Rufenacht DA, Tsutsumi S. Poly-vinyl alcohol hydrogel vascular models for in vitro aneurysm simulations: the key to low friction surfaces. Technol Health Care. 2004;12(3): 225-233.

32. Dähring H, Grandke J, Teichgräber U, Hilger I. Improved hyperthermia treatment of tumors under consideration of magnetic nanoparticle distribution using micro-CT imaging. Mol Imaging Biol. 2015;17(6): 763-769.

33. Sapareto SA, Dewey WC. Thermal dose determination in cancer therapy. Int J Radiat Oncol Biol Phys. 1984;10(6):787-800.

34. Genestier L, Paillot R, Quemeneur L, Izeradjene K, Revillard JP. Mechanisms of action of methotrexate. Immunopharmacology. 2000;47(2-3): $247-257$.

35. Joannon P, Oviedo I, Campbell M, Tordecilla J. High-dose methotrexate therapy of childhood acute lymphoblastic leukemia: lack of relation between serum methotrexate concentration and creatinine clearance. Pediatr Blood Cancer. 2004;43(1):17-22.

36. Moghimi SM, Hunter AC, Murray JC. Nanomedicine: current status and future prospects. FASEB J. 2005;19(3):311-330.

37. Albanese A, Tang PS, Chan WC. The effect of nanoparticle size, shape, and surface chemistry on biological systems. Annu Rev Biomed Eng. 2012;14:1-16

38. Violet M, Delattre L, Tardivel M, et al. A major role for Tau in neuronal DNA and RNA protection in vivo under physiological and hyperthermic conditions. Front Cell Neurosci. 2014;8:84.

39. Cooper MJ, Haluschak JJ, Johnson D, et al. p53 mutations in bladder carcinoma cell lines. Oncol Res. 1994;6(12):569-579.

40. Markl ID, Jones PA. Presence and location of TP53 mutation determines pattern of CDKN2A/ARF pathway inactivation in bladder cancer. Cancer Res. 1998;58(23):5348-5353.

41. Esrig D, Elmajian D, Groshen S, et al. Accumulation of nuclear p53 and tumor progression in bladder cancer. N Engl J Med. 1994;331(19): 1259-1264.

42. Kraljevic PS, Marjanovic M, Poznic M, Kralj M. Adenovirally mediated p53 overexpression diversely influence the cell cycle of HEp-2 and CAL 27 cell lines upon cisplatin and methotrexate treatment. $J$ Cancer Res Clin Oncol. 2009;135(12):1747-1761.

43. Bhonde MR, Hanski ML, Budczies J, et al. DNA damage-induced expression of p53 suppresses mitotic checkpoint kinase hMps1: the lack of this suppression in p53MUT cells contributes to apoptosis. $J$ Biol Chem. 2006;281(13):8675-8685.

44. Xiong Y, Hannon GJ, Zhang H, Casso D, Kobayashi R, Beach D. P21 Is a universal inhibitor of cyclin kinases. Nature. 1993;366(6456): 701-704.

45. Donnellan R, Chetty R. Cyclin E in human cancers. FASEB J. 1999;13(8): 773-780.

46. Martín-caballero J, Flores JM, García-palencia P, Serrano M. Tumor susceptibility of p21(Waf1/Cip1)-deficient mice. Cancer Res. 2001;61(16): 6234-6238.

47. Hall MC, Li Y, Pong RC, Ely B, Sagalowsky AI, Hsieh JT. The growth inhibitory effect of p21 adenovirus on human bladder cancer cells. J Urol. 2000;163(3):1033-1038.

48. Dong Y, Chi SL, Borowsky AD, Fan Y, Weiss RH. Cytosolic p21Waf1/ Cip1 increases cell cycle transit in vascular smooth muscle cells. Cell Signal. 2004;16(2):263-269. 
49. Yuan SS, Chang HL, Chen HW, et al. Selective cytotoxicity of squamocin on T24 bladder cancer cells at the S-phase via a Bax-, Bad-, and caspase-3-related pathways. Life Sci. 2006;78(8):869-874.

50. Klopfleisch R, Gruber AD. Differential expression of cell cycle regulators p21, p27 and p53 in metastasizing canine mammary adenocarcinomas versus normal mammary glands. Res Vet Sci. 2009;87(1): 91-96.

51. Putt KS, Chen GW, Pearson JM, et al. Small-molecule activation of procaspase-3 to caspase-3 as a personalized anticancer strategy. Nat Chem Biol. 2006;2(10):543-550.

52. Boulares AH, Yakovlev AG, Ivanova V, et al. Role of poly(ADP-ribose) polymerase (PARP) cleavage in apoptosis. Caspase 3-resistant PARP mutant increases rates of apoptosis in transfected cells. J Biol Chem. 1999;274(33):22932-22940.

53. Oliver FJ, de la Rubia G, Rolli V, Ruiz-Ruiz MC, de Murcia G, Murcia JM. Importance of Poly(ADP-ribose) polymerase and its cleavage in apoptosis. Lesson from an uncleavable mutant. J Biol Chem. 1998;273(50): 33533-33539.

54. Hu H, Jiang C, Li G, Lü J. PKB/AKT and ERK regulation of caspasemediated apoptosis by methylseleninic acid in $\mathrm{LNCaP}$ prostate cancer cells. Carcinogenesis. 2005;26(8):1374-1381.

55. Richard DE, Berra E, Gothié E, Roux D, Pouysségur J. p42/p44 mitogen-activated protein kinases phosphorylate hypoxia-inducible factor 1alpha (HIF-1alpha) and enhance the transcriptional activity of HIF-1. J Biol Chem. 1999;274(46):32631-32637.

56. Vantaggiato C, Formentini I, Bondanza A, Bonini C, Naldini L, Brambilla R. ERK1 and ERK2 mitogen-activated protein kinases affect Ras-dependent cell signaling differentially. J Biol. 2006;5(5):14.

57. Platt FM, Hurst CD, Taylor CF, Gregory WM, Harnden P, Knowles MA. Spectrum of phosphatidylinositol 3-kinase pathway gene alterations in bladder cancer. Clin Cancer Res. 2009;15(19):6008-6017.

58. Fujio Y, Nguyen T, Wencker D, Kitsis RN, Walsh K. Akt promotes survival of cardiomyocytes in vitro and protects against ischemiareperfusion injury in mouse heart. Circulation. 2000;101(6):660-667.

59. Fujio Y, Guo K, Mano T, Mitsuuchi Y, Testa JR, Walsh K. Cell cycle withdrawal promotes myogenic induction of Akt, a positive modulator of myocyte survival. Mol Cell Biol. 1999;19(7):5073-5082.

60. Dudek H, Datta SR, Franke TF, et al. Regulation of neuronal survival by the serine-threonine protein kinase Akt. Science. 1997;275(5300): 661-665.

61. Somanath PR, Razorenova OV, Chen J, Byzova TV. Akt1 in endothelial cell and angiogenesis. Cell Cycle. 2006;5(5):512-518.

62. Shiojima I, Walsh K. Role of Akt signaling in vascular homeostasis and angiogenesis. Circ Res. 2002;90(12):1243-1250.

63. Kitamura T, Asai N, Enomoto A, et al. Regulation of VEGF-mediated angiogenesis by the Akt/PKB substrate Girdin. Nat Cell Biol. 2008; 10(3):329-337.

64. Vaux DL, Cory S, Adams JM. Bcl-2 gene promotes haemopoietic cell survival and cooperates with c-myc to immortalize pre-B cells. Nature. 1988;335(6189):440-442.

65. McDonnell TJ, Deane N, Platt FM, et al. bcl-2-immunoglobulin transgenic mice demonstrate extended B cell survival and follicular lymphoproliferation. Cell. 1989;57(1):79-88.

66. Modugno M, Banfi P, Gasparri F, et al. Mcl-1 antagonism Is a potential therapeutic strategy in a subset of solid cancers. Exp Cell Res. 2015; 332(2):267-277.

67. Palve V, Mallick S, Ghaisas G, Kannan S, Teni T. Overexpression of Mcl-1L splice variant is associated with poor prognosis and chemoresistance in oral cancers. PLoS One. 2014;9(11):e111927.

68. Tavaria M, Gabriele T, Kola I, Anderson RL. A hitchhiker's guide to the human Hsp70 family. Cell Stress Chaperones. 1996;1(1):23-28.

69. Morano KA. New tricks for an old dog: the evolving world of Hsp70. Ann N Y Acad Sci. 2007;1113(1):1-14.

70. García-Cardeña G, Fan R, Shah V, et al. Dynamic activation of endothelial nitric oxide synthase by Hsp90. Nature. 1998;392(6678):821-824.

71. Semenza GL. Targeting HIF-1 for cancer therapy. Nat Rev Cancer. 2003;3(10):721-732.
72. Wang GL, Jiang BH, Rue EA, Semenza GL. Hypoxia-inducible factor 1 is a basic-helix-loop-helix-PAS heterodimer regulated by cellular $\mathrm{O} 2$ tension. Proc Natl Acad Sci U S A. 1995;92(12):5510-5514.

73. Iyer NV, Kotch LE, Agani F, et al. Cellular and developmental control of O2 homeostasis by hypoxia-inducible factor 1 alpha. Genes Dev. 1998; 12(2):149-162.

74. Bos R, van der Groep P, Greijer AE, et al. Levels of hypoxia-inducible factor-1alpha independently predict prognosis in patients with lymph node negative breast carcinoma. Cancer. 2003;97(6):1573-1581.

75. Zhong H, De Marzo AM, Laughner E, et al. Overexpression of hypoxiainducible factor 1alpha in common human cancers and their metastases. Cancer Res. 1999;59(22):5830-5835.

76. Palmer LA, Semenza GL, Stoler MH, Johns RA. Hypoxia induces type II NOS gene expression in pulmonary artery endothelial cells via HIF-1. Am J Physiol. 1998;274(2 Pt 1):L212-L219.

77. Wieczorek E, Jablonowski Z, Tomasik B, et al. MMP, VEGF and TIMP as prognostic factors in recurring bladder cancer. Clin Biochem. 2015;48(18):1235-1240.

78. Olsson AK, Dimberg A, Kreuger J, Claesson-Welsh L. VEGF receptor signalling - in control of vascular function. Nat Rev Mol Cell Biol. 2006;7(5):359-371.

79. Clauss M. Molecular biology of the VEGF and the VEGF receptor family. Semin Thromb Hemost. 2000;26(5):561-569.

80. Claesson-Welsh L. Signal transduction by vascular endothelial growth factor receptors. Biochem Soc Transact. 2003;31(Pt 1):20-24.

81. Fong GH, Rossant J, Gertsenstein M, Breitman ML. Role of the Flt-1 receptor tyrosine kinase in regulating the assembly of vascular endothelium. Nature. 1995;376(6535):66-70.

82. Kerbel RS, Yu J, Tran J, et al. Possible mechanisms of acquired resistance to anti-angiogenic drugs: implications for the use of combination therapy approaches. Cancer Metastasis Rev. 2001;20(1-2):79-86.

83. Miller KD, Sweeney CJ, Sledge GW. Can tumor angiogenesis be inhibited without resistance? In: Clauss M, Breier G, editors. Mechanisms of Angiogenesis. Vol 94. Experientia Supplementum. Basel, Switzerland: Birkhäuser-Verlag; 2005:95-112.

84. Casanovas O, Hicklin DJ, Bergers G, Hanahan D. Drug resistance by evasion of antiangiogenic targeting of VEGF signaling in late-stage pancreatic islet tumors. Cancer Cell. 2005;8(4):299-309.

85. Mook OR, Frederiks WM, Van Noorden CJ. The role of gelatinases in colorectal cancer progression and metastasis. Biochim Biophys Acta. 2004;1705(2):69-89.

86. Björklund M, Koivunen E. Gelatinase-mediated migration and invasion of cancer cells. Biochim Biophys Acta. 2005;1755(1):37-69.

87. Giannelli G, Falk-Marzillier J, Schiraldi O, Stetler-Stevenson WG, Quaranta V. Induction of cell migration by matrix metalloprotease-2 cleavage of laminin-5. Science. 1997;277(5323):225-228.

88. Vu TH, Shipley JM, Bergers G, et al. MMP-9/gelatinase B is a key regulator of growth plate angiogenesis and apoptosis of hypertrophic chondrocytes. Cell. 1998;93(3):411-422.

89. Heissig B, Hattori K, Dias S, et al. Recruitment of stem and progenitor cells from the bone marrow niche requires MMP-9 mediated release of kit-ligand. Cell. 2002;109:625-637.

90. Gialeli C, Theocharis AD, Karamanos NK. Roles of matrix metalloproteinases in cancer progression and their pharmacological targeting. FEBS J. 2011;278(1):16-27.

91. Minella AC, Loeb KR, Knecht A, et al. Cyclin E phosphorylation regulates cell proliferation in hematopoietic and epithelial lineages in vivo. Genes Dev. 2008;22(12):1677-1689.

92. Soucek T, Pusch O, Hengstschläger-Ottnad E, Adams PD, Hengstschläger M. Deregulated expression of E2F-1 induces cyclin A- and E-associated kinase activities independently from cell cycle position. Oncogene. 1997;14(19):2251-2257.

93. American Cancer Society AC. Bladder Cancer. Available from: http://www.cancer.org/Cancer/BladderCancer/DetailedGuide/index. Accessed February 1, 2016. 


\section{Supplementary materials}

A

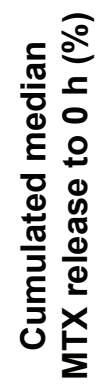

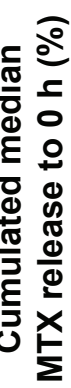

0.10
0.08
0.06
0.04
0.02
0.00

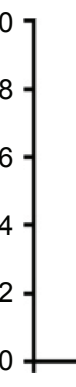

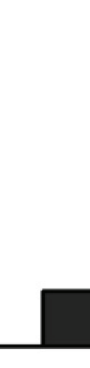

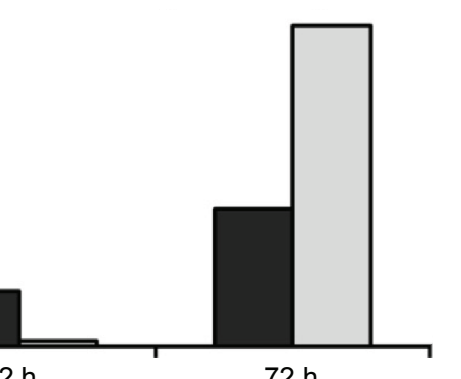

B

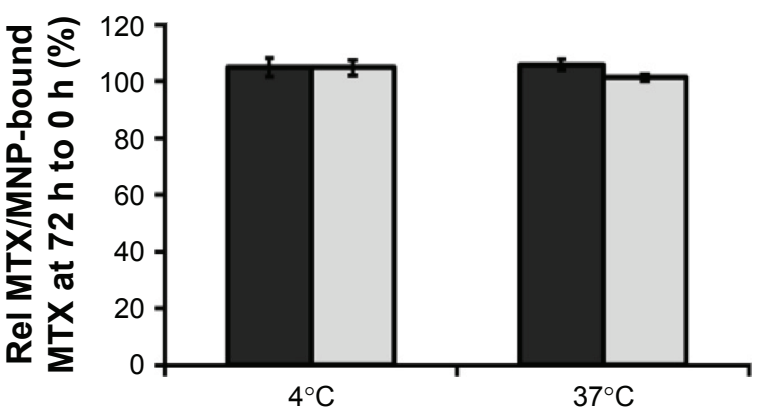

$\mathrm{pH} 5 \quad \mathbf{0} \mathrm{pH} 7.4$

Figure SI The influence of $\mathrm{pH}$ and time $(\mathbf{A})$ and the $\mathrm{pH}$ and temperature $(\mathbf{B})$ onto the stability of MTX/MNPs.

Notes: MTX/MNPs were incubated for the stated time under the corresponding conditions. $0 \mathrm{~h}$ : amount of MTX/MNP-bound MTX directly after coupling process ( $\geq 3$ ) Abbreviations: MNPs, magnetic nanoparticles; MTX, methotrexate.
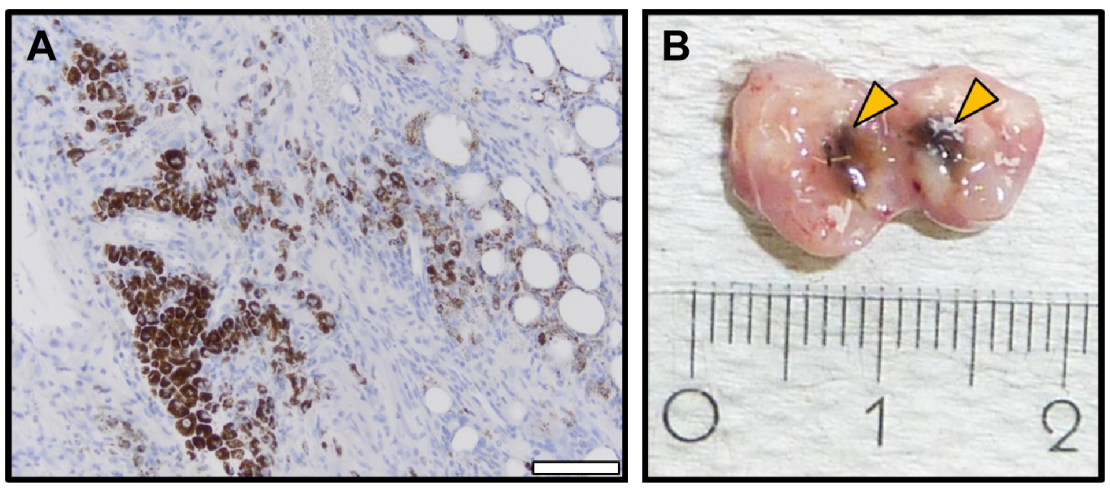

Figure S2 Microscopic (A) and macroscopic (B) MTX/MNP depositions in the tumor at $28 \mathrm{~d}$ after MTX/MNP application.

Notes: (A) Hematoxylin and eosin staining of $3 \mu \mathrm{m}$ tumor sections (FFPE) indicated diffuse and cytoplasmatic localization of intratumorally applied MTX/MNPs, allowing a repetition of AMF treatment. (B) Macroscopic depictions of the dissected tumor reveled regions with high MTX/MNP depositions (arrow). Blue, nuclei; brown, MTX/MNPs. Scale bar: $50 \mu \mathrm{m}$.

Abbreviations: AMF, alternating magnetic field; FFPE, formalin-fixed and paraffin embedded; MNPs, magnetic nanoparticles; MTX, methotrexate.

\section{Publish your work in this journal}

The International Journal of Nanomedicine is an international, peerreviewed journal focusing on the application of nanotechnology in diagnostics, therapeutics, and drug delivery systems throughou the biomedical field. This journal is indexed on PubMed Central, MedLine, CAS, SciSearch ${ }^{\circledR}$, Current Contents ${ }^{\circledR} /$ Clinical Medicine,
Journal Citation Reports/Science Edition, EMBase, Scopus and the Elsevier Bibliographic databases. The manuscript management system is completely online and includes a very quick and fair peer-review system, which is all easy to use. Visit http://www.dovepress.com/ testimonials.php to read real quotes from published authors 